\title{
Withdrawing attention at little or no cost: Detection and discrimination tasks
}

\author{
JOCHEN BRAUN \\ California Institute of Technology, Pasadena, California \\ and \\ BELA JULESZ \\ Rutgers University, Piscataway, New Jersey
}

\begin{abstract}
We used a concurrent-task paradigm to investigate the attentional cost of simple visual tasks. As in earlier studies, we found that detecting a unique orientation in an array of oriented elements ("popout") carries little or no attentional cost. Surprisingly, this is true at all levels of performance and holds even when pop-out is barely discriminable. We discuss this finding in the context of our previous report that the attentional cost of stimulus detection is strongly influenced by the presence and nature of other stimuli in the display (Braun, 1994b). For discrimination tasks, we obtained a similarly mixed outcome: Discrimination of letter shape carried a high attentional cost whereas discrimination of color and orientation did not. Taken together, these findings lead us to modify our earlier position on the attentional costs of detection and discrimination tasks (Sagi \& Julesz, 1985). We now believe that observers enjoy a significant degree of "ambient" visual awareness outside the focus of attention, permitting them to both detect and discriminate certain visual information. We hypothesize that the information in question is selected by a competition for saliency at the level of early vision.
\end{abstract}

It has long been recognized that visual perception is influenced by the observer's attentional state (Helmholtz, 1850/1962; James, 1890/1981). Psychophysical studies show that attention enhances visual sensitivity for stimuli that are relevant to the observer and his/her behavior (e.g., Bashinski \& Bacharach, 1980; Downing, 1988; Müller \& Findlay, 1987; Shaw, 1984) and, further, that this effect is large for a single relevant stimulus but far smaller for several relevant stimuli (Bonnel \& Miller, 1994; Duncan, 1980b; Sperling \& Melchner, 1978). The latter results confirm the subjective impression that attention is most effective when it focuses on a single stimulus or location. The need to maximize sensitivity by focusing attention also explains why visual performance is often "serial," that is, why the presence of additional display elements often prolongs the requisite viewing time (Bergen \& Julesz, 1983; Julesz, 1981; Sagi \& Julesz, 1985; Treisman \& Gelade, 1980).

However, attention does not benefit all types of visual performance equally. For example, luminance detection generally fails to exhibit an attentional sensitivity gain (Bonnel, Stein, \& Bertucci, 1994; Müller \& Findlay, 1987;

We thank Nancy Kanwisher, Christof Koch, and Pietro Perona for discussions, and Leslie Brothers, John Duncan, Charles Folk, Christof Nothdurft, Jeremy Wolfe, and Steven Yantis for commenting on various versions of the manuscript. In addition, J.B. wishes to thank Nancy Kanwisher for her encouragement. This work was supported by ONR Grant N00014-89-J1192 to David Van Essen and B.J., NSF Grart IBN9312224 to J.B. and Christof Koch, and an AFOSR Grant to C. Koch. Correspondence should be addressed to J. Braun, California Institute of Technology, Division of Biology 139-74, Pasadena, CA 91125 (e-mail: achim@klab.caltech.edu).
Shaw, 1984; but see Downing, 1988). Indeed, many detection tasks are performed in a "parallel" fashion - that is, the requisite viewing time is not prolonged by additional display elements (Bergen \& Julesz, 1983; Julesz, 1981; Sagi \& Julesz, 1985; Treisman \& Gelade, 1980; Treisman \& Gormican, 1988). In general, performance is parallel when a simple feature-luminance, color, motion, disparity, orientation, size, and presence of line terminators-distinguishes the target from other display elements (Braun, 1994a; Bravo \& Nakayama, 1992; Dick, Ullman, \& Sagi, 1987; Enns \& Rensink, 1990; Gurnsey \& Browse, 1987; Julesz, 1981, 1984; Nakayama \& Mackeben, 1989; Nakayama \& Silverman, 1986; Sun \& Perona, 1996; Treisman \& Gormican, 1988; Williams \& Julesz, 1991; for overviews, see Julesz, 1991; Watt, 1991; Wolfe, in press). This seemingly automatic and effortless detection of unique features is often called "pop-out" (Treisman \& Gelade, 1980).

Here we investigate the extent to which pop-out and related visual experiences occur "outside" the focus of attention. Our point of departure is the intuition that the richness of visual experience derives not only from a narrow focus of attention but also from an "ambient" visual awareness of unattended parts of the visual scene, and that pop-out is a major component of this ambient visual awareness. This intuition is supported by previous experiments in which a typical pop-out detection was compared with a typical task requiring focused attention (Braun \& Sagi, 1990, 1991). Specifically, we compared detection of a unique orientation in a dense array of oriented elements (Nothdurft, 1991; Sagi, 1990; Sagi \& Julesz, 1985, 1987) with discrimination of letter shape 
(Bergen \& Julesz, 1983; Duncan, Ward, \& Shapiro, 1994; Kröse \& Julesz, 1989). Using brief presentation times and perceptual masking, we found that independent discrimination of two (distant) letters requires approximately twice the presentation time as discriminating a single letter. Independent detection of two (distant) popouts, however, requires approximately the same presentation time as detecting a single pop-out. Most importantly, discriminating a letter and detecting a pop-out requires also approximately the same presentation time as either task by itself. Similar results were obtained with pop-out of features other than orientation (Ben-Av, Sagi, \& Braun, 1992; Braun, 1994a).

These findings suggest that pop-out is experienced even while attention is engaged by a letter discrimination elsewhere in the display, consistent with the idea that there is some ambient visual awareness that is independent of attention. However, the most straightforward interpretation of these results - that the experience and voluntary report of pop-out impose no attentional cost whatsoever-is at variance with established views on attention. Indeed, it is widely held that attention mediates all visual experience that is sufficiently detailed to be voluntarily reported (Bravo \& Nakayama, 1992; Duncan, $1980 \mathrm{~b}$; Treisman, 1988, 1993). With respect to pop-out, it has been proposed that attention spontaneously focuses on any display element with a unique feature, and that this involuntary focusing of attention is experienced as pop-out (Koch \& Ullman, 1985; Robinson \& Petersen, 1992). In this case, pop-out should entail a substantial attentional cost, since attention would be temporarily prevented from focusing on other parts of the display (Treisman, 1993). A more likely possibility is that partial attention suffices for the experience of pop-out (Bravo \& Nakayama, 1992; Nakayama \& Mackeben, 1989; Treisman, 1993). This would be consistent with the idea that attention must focus narrowly on poorly discriminable stimuli but may spread widely for more readily discriminable stimuli, such as, presumably, one with a unique feature (Eriksen \& St. James, 1986; LaBerge \& Brown, 1989). In this case, pop-out would entail only a modest attentional cost, since attention would remain partially available in other parts of the display.

The first aim of the present study was to decide between these alternatives by quantifying the attentional cost of pop-out as well as possible. To this end, we employed an improved concurrent-task paradigm in which attention is engaged by a particularly demanding primary task so that essentially no attention remains available for a secondary task ("secondary task paradigm," Kahneman, 1973). We confirmed the effectiveness of this paradigm by establishing the attention-operating characteristic (AOC; Sperling \& Dosher, 1986; Sperling \& Melchner, 1978) of the primary task with a secondary task known to engage attention (letter discrimination). Next we established the AOC of the primary task with the detection of pop-out as a secondary task. In contrast to earlier studies (Braun \& Sagi, 1990, 1991), we inves- tigated pop-out over a wide range of discriminability (by varying the orientation difference between the target and other display elements). The rationale is that if pop-out entails an attentional cost, this cost should increase with decreasing discriminability. This follows from the theoretical arguments of Norman and Bobrow (1975; see also Navon \& Gopher, 1979): As long as discriminability is high, performance of a psychophysical task may saturate before there is a measurable demand on attention (datalimited regime). When discriminability is low, however, comparable performance requires increased and, in the extreme case, full attention (resource-limited regime). The results showed that pop-out imposes little or no attentional cost at all levels of discriminability.

The second aim of our study was to investigate the attentional cost of reporting simple attributes of a pop-out, for example, color or orientation. Accordingly, this part of the study focused on discrimination rather than detection tasks. Specifically, we presented stimuli of varying orientation and/or color in the visual periphery and asked observers to discriminate these attributes in a concurrent-task situation - that is, with attention focused at the center of the visual field. An essential aspect of the design was that the stimuli in question popped out from the display. The results suggest that discriminating the orientation and color of up to two pop-out stimuli indeed entails little or no attentional cost. This leads us to modify our earlier view that only location, but not attributes like orientation and color, are discriminable outside the focus of attention (Sagi \& Julesz, 1985; Braun \& Sagi, 1990). The results also show, however, that complex attributes such as letter shape are discriminable only at considerable attentional cost.

The discussion of these results takes into account our previously reported finding that the attentional cost of detection tasks is strongly influenced by the presence and nature of other stimuli in the display (Braun, 1994b). Together, our concurrent-task results leave little doubt that observers enjoy significant visual capabilities outside the focus of attention. We hypothesize that this "ambient vision" is intimately connected to the mechanisms that underlie visual saliency (Koch \& Ullman, 1985; Robinson \& Petersen, 1992).

Some of this work has been reported in preliminary form (Braun \& Julesz, 1992, 1994).

\section{GENERAL METHOD}

\section{Subjects}

Eighteen California Institute of Technology undergraduates served as subjects (B.E., B.R., C.C., C.H., C.O., D.A., D.S., G.A., G.C., J.E., J.O., L.N., M.G., M.I., P.G., S.A., S.T., and T.S.). Each subject enrolled for at least 15 daily sessions of 1 to $1.5 \mathrm{~h}$ and received payment of $\$ 200$. Subjects reported normal color vision and visual acuity (sometimes with corrective lenses), but underwent no tests in this respect. All subjects received several days of practice before data collection and were naive as to the purpose of the experiment. Subjects were highly motivated and regarded the experiments (some of which were very demanding) as a challenging arcade game. 


\section{Equipment}

Stimuli were generated by a raster display system (Adage 3106) with a Microvax II (Digital) as host computer and displayed on a high-resolution color monitor (Hitachi). Monitor resolution was $512 \times 512$ pixels. Lightness and color of each pixel were determined by $3 \times 8$ bit RGB values. The frame rate was $55.5 \mathrm{~Hz}$, permitting display times to be varied in steps of $18 \mathrm{msec}$. Viewing was binocular, from a distance of approximately $110 \mathrm{~cm}$, resulting in a display of approximately $14.5^{\circ} \times 14.5^{\circ}$ of visual angle. Thus, a distance of 100 pixels corresponded to approximately $2.83^{\circ}$ of visual angle (neglecting projective distortion). No chinrest was used. Before each trial, subjects fixated a mark at the display center. Because of the short duration of the trial, there was no need to otherwise control eye position. Background luminosity differed among experiments, and ambient illumination was approximately $5 \mathrm{~cd} / \mathrm{m}^{2}$. Responses were unspeeded and were entered on a computer keyboard, with incorrect responses eliciting immediate auditory feedback.

\section{Perceptual Masking}

The effective presentation time of a stimulus was determined not by the physical presentation time but by the time between onset of the stimulus and onset of the mask, or stimulus onset asynchrony (SOA): The onset of the mask limited visual persistence of the stimulus. SOA was adjusted individually for each task and subject under single-task conditions (see below). This ensured that performance was below ceiling even with attention fully focused on a task.

Stimulus displays were presented for $36 \mathrm{msec}$ and mask displays for $72 \mathrm{msec}$. The intervening interval of background luminosity lasted from 18 to $256 \mathrm{msec}$, depending on task and subject. In experiments with multiple tasks, different stimulus regions were masked at different times, resulting in different SOAs for the associated tasks.

\section{Psychophysical Performance}

All tasks involved the discrimination of two stimulus alternatives, $A$ and $B$. Correct and incorrect responses were counted separately for each stimulus alternative and two fractions of correct responses, $f_{A}$ and $f_{B}$, were obtained for each block of trials. These two fractions were combined to yield a representative performance value, $p_{A, B}$ :

$$
\begin{aligned}
& p_{A, B}=100 F\left(\frac{1}{2} F^{-1}\left(f_{A}\right)+\frac{1}{2} F^{-1}\left(f_{B}\right)\right) \\
& F(z)=\frac{1}{\sqrt{\pi}} \int_{-\infty}^{z} e^{-t^{2}} d t,
\end{aligned}
$$

where $F^{-1}($ ) denotes the inverse function of the normal distribution $F\left(\right.$ ). Note that, unlike the fractions correct $f_{A}$ and $f_{B}$, the representative performance $p_{A, B}$ is independent of the subject's criterion. In fact, $p_{A, B}$ is the discriminability $d^{\prime}$ of signal detection theory (Green \& Swets, 1966; Macmillan \& Creelman, 1991) expressed in units of percentage correct. In other words, $p_{A, B}$ is the performance that would have been obtained if the decision process had conformed to signal detection theory and the criterion had been set exactly between the mean signal levels of alternatives $A$ and $B$.

\section{Concurrent-Task Paradigm}

Concurrent-task experiments (Experiments 2-6) were conducted as described in Braun (1994b). Subjects were asked, in separate blocks of trials, to carry out the one task, the other task, or both. The display remained the same and always contained all stimuli. For some blocks, subjects were asked to "concentrate" on one task and to "disregard" the other, and to respond once after each trial. This instruction permitted subjects to focus attention on one task and produced one single-task performance value. In other blocks, subjects were asked to give one task ("primary task") priority over the other ("secondary task"), and to respond twice after each trial. This instruction forced subjects to divide attention unequally between the two tasks and produced two double-task performance values. Whenever double-task performance of the primary task fell below single-task performance of that task, the instructions regarding task priority were repeated. In this way, we usually obtained almost identical single- and double-task performance on the primary task.

\section{AOCs and Performance-Resource Functions}

In the concurrent-task situation, the subject can voluntarily alter the way in which attention is divided between tasks. Thus, there is a whole family of possible outcomes, one for every possible division of attention. For this reason, concurrent-task results are best reported in the form of an $A O C$, which describes how the performance of both tasks varies with the division of attention. The AOC of a task combination may permit certain inferences about the performance-resource functions (PRFs) of the tasks in question, which describe performance as a function of the fraction of attention devoted to a task (Norman \& Bobrow, 1975; Sperling \& Dosher, 1986; Sperling \& Melchner, 1978). To illustrate these notions, the PRFs and AOCs of several hypothetical task combinations are graphed in Figure 1.

\section{Variability of the Division of Attention Between Trials}

Several steps were taken to monitor variability in the division of attention between concurrent tasks. If the division varies from trial to trial, one would expect success or failure of one task to be negatively correlated with success or failure of the other. Let $n_{i j}$ be the number of trials with outcomes $i$ and $j$ of the two tasks, respectively $(i, j=1$ for a correct response and $i, j=0$ for an incorrect response). If the two tasks are performed independently, so that their outcomes are not correlated, then the expected number of trials with outcome $i, j, \bar{n}_{i j}$, is given by

$$
\bar{n}_{i j}=\frac{\sum_{k} n_{k j} \sum_{l} n_{i l}}{\sum_{k, l} n_{k l}} .
$$

If the two tasks are not performed independently, and their outcomes are (negatively or positively) correlated, then the actual number of trials with outcomes $i, j$ will differ from the expected values. In the case of a negative correlation, there will be fewer than expected trials with identical outcomes on both tasks $\left(n_{00}<\bar{n}_{00}\right.$ and $n_{11}<\bar{n}_{11}$ ) and more than expected trials with different outcomes on both tasks $\left(n_{01}>\bar{n}_{01}\right.$ and $\left.n_{10}>\bar{n}_{10}\right)$. The statistical significance of any difference between actual and expected values is given by the $\chi^{2}$ measure of association ( $1 d f ;$ W. H. Press, Teukolsky, Vetterling, \& Flannery, 1992):

$$
\chi^{2}=\sum_{i, j} \frac{\left(n_{i j}-\bar{n}_{i j}\right)^{2}}{\bar{n}_{i j}} .
$$

\section{Variability of the Division of Attention Between Blocks}

If the division of attention is approximately constant during each block of trials, but varies between blocks, one would expect the block performance of one task to be (negatively) correlated with the block performance of the other. Let $N_{u v}$ be the number of blocks in which performance of the two tasks is $u$ and $v$, respectively, where $u, v \in(0.0,100.0)$. If the number of blocks is finite, $N_{u v}$ will be zero for most $u, v$. Hence, a nonparametric measure such as Kendall's $\tau$ must be used to determine the statistical significance of any correlation between $u$ and $v$ (W. H. Press et al., 1992).

\section{Compatibility Index}

When two tasks are carried out concurrently, performance is often lower than when each of the tasks is carried out by itself. One way to quantify this reduction in performance is to directly compare 
a

PRF

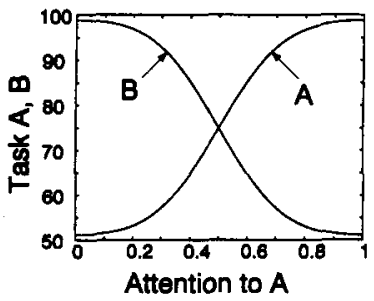

b

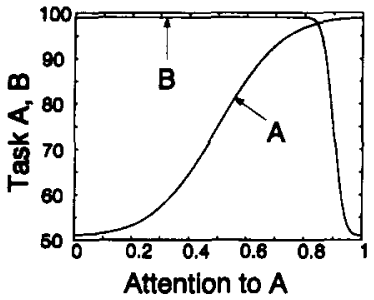

C

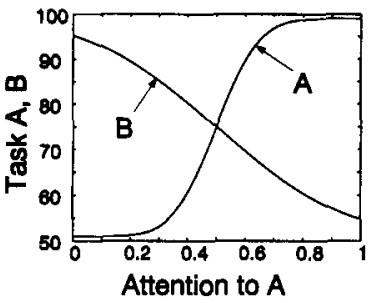

AOC
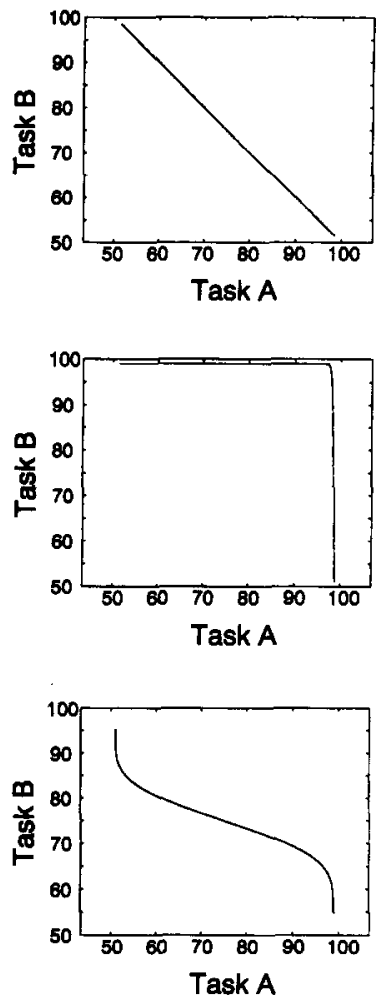

Figure 1. Analysis of concurrent-task experiments. The relationship between performance and resources (e.g., attention) devoted to a task is the performance-resource function (PRF). Here, performance is quantified as the fraction of correct responses and chance performance is assumed to be .5 . The amount of attention devoted to a task is quantified as a fraction of the total, which is assumed to be constant. If attention is divided between tasks, their PRFs jointly determine how performance of one task varies with performance of the other. This relationship is the attention-operating characteristic (AOC). (a) Tasks $A$ and $B$ depend equally on attention and have identical PRFs; the resulting $A O C$ is a diagonal line, indicating that only one task can be performed well at the same time. (b) Task $B$ requires much less attention than does $A$, allowing attention to remain almost undivided on $A$. The resulting $A O C$ forms almost a square, indicating that both tasks can be performed well at the same time. (c) Tasks $A$ and $B$ depend on attention to a comparable degree, but do not have identical PRFs, resulting in an asymmetric AOC. Surprisingly, this case has never been observed.

single- and double-task performance of each task and to independently assess the statistical significance of each difference. A more sensitive method is to define a compatibility index $C_{i}$,

$$
C_{i}=\frac{d_{A}^{i}-c_{A}}{\overline{s_{A}}-c_{A}}+\frac{d_{B}^{i}-c_{B}}{\overline{s_{B}}-c_{B}}-1
$$

where $d_{A}^{i}$ and $d_{B}^{i}$ are the respective performance of tasks $A$ and $B$ in touble-task block $i, \overline{s_{A}}$ and $\overline{s_{B}}$ are the respective average perfornances in all single-task blocks, and $c_{A}$ and $c_{B}$ are the respective 'evels of chance performance. A $C_{i}$ of unity indicates that doubleand single-task performance are the same, implying no competition or attention. $\mathrm{A} C_{i}$ of zero indicates that, when one task is performed it its best, the other task is performed at chance, implying maximal competition for attention. The relation between the compatibility index and the AOC is illustrated in Figure 2.

\section{Practice Effects and Procedure}

For many psychophysical tasks, a given subject's performance will improve with practice, especially when the task is performed daily for several weeks, as was the case in the present study. However, not all types of tasks are equally susceptible to practice. Among the tasks investigated here, the detection of pop-out seemed to be the most susceptible, and the discrimination of letter shape the least susceptible to improvement by practice. Interestingly, for trained subjects, almost none of the improvement occurs within the 1-1.5 h of a single session, but most occurs only after 9-12 h have elapsed (Karni \& Sagi, 1993; Karni, Tanne, Rubenstein, Askenasy, \& Sagi, 1994). Thus, performance tends to "jump" between one session and the next, rather than to "creep up" continuously during every session.

We took three steps to minimize practice effects in our concurrent task experiments: (1) Subjects received two or three practice sessions before data were collected. (2) Data on any given display type and presentation time were collected as quickly as possible with one to four dedicated sessions (except Experiment 2). (3) In each session, subjects performed at least one block of each single task as well as several blocks of the double task. Accordingly, even if performance had improved between the first and the last sessions, this would not have compromised the comparison of single- and double-task performance. However, significant differences between first and last sessions were almost never observed.

In Experiment 2, we used highly experienced subjects who had previously participated in concurrent-task experiments involving the letter task. These included experiments in which there was little or no interference between tasks (compatibility index near unity). In the present experiment, there was substantial inference between tasks (compatibility index near zero). Thus the present results cannot be attributed to lack of practice.

In Experiments 3, 4, and 5, data were collected beginning with more and ending with less discriminable displays. That is, subjects began with orientation differences of $45^{\circ}$ and ended with orientation differences of $15^{\circ}$ in Experiments 3 and 4, and began with stronger and ended with weaker hues in Experiment 5 . As a result, any improvement with practice would have led us to underestimate the difference between more discriminable and less discriminable displays.

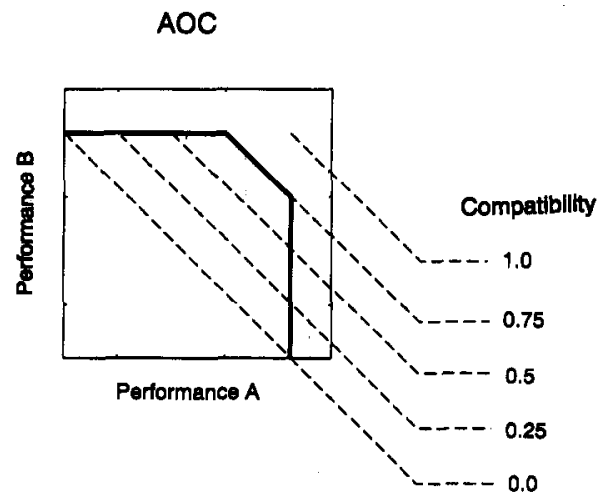

Figure 2. Illustration of the compatibility index. To characterize the degree to which two visual tasks pose conflicting demands for attention, one can compute a compatibility index from the respective single-task and double-task performances (see General Method). Essentially, this index parameterizes the shape of the attention-operating characteristic (AOC), being unity for a square $A O C$ and zero for a diagonal $A O C$. 
The 3 subjects who participated in several experiments (J.O., M.I., S.A.) performed first in Experiment 6, next in Experiment 3, and last in Experiment 5. Accordingly, the somewhat stronger interference between concurrent tasks exhibited by these and other subjects in Experiment 5 is unlikely to have been caused by lack of practice.

\section{EXPERIMENT 1 Letter Task Involves Serial Processing}

Presented with a cluster of letters, subjects detect the presence or absence of one "odd" letter (letter task). Visual persistence was limited by masking, and performance was determined as a function of letter number and SOA.

\section{Method}

The stimulus display (Figure 3a) contained one or more letter targets in front of a dark background (luminosity approximately $\left.5 \mathrm{~cd} / \mathrm{m}^{2}\right)$. Letter targets appeared at seven possible positions $(r, \theta)$

8

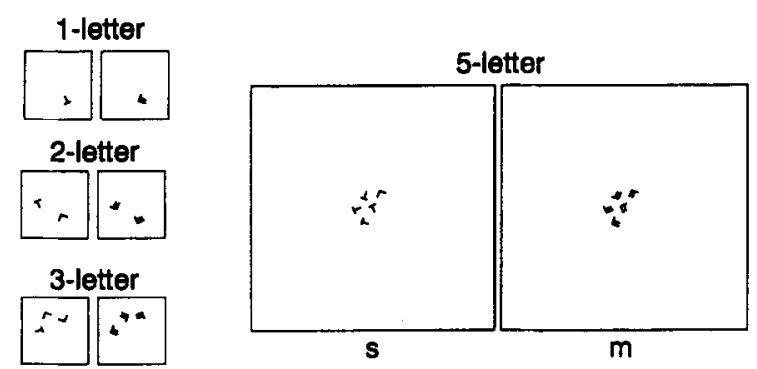

b

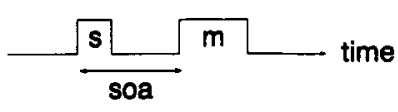

c

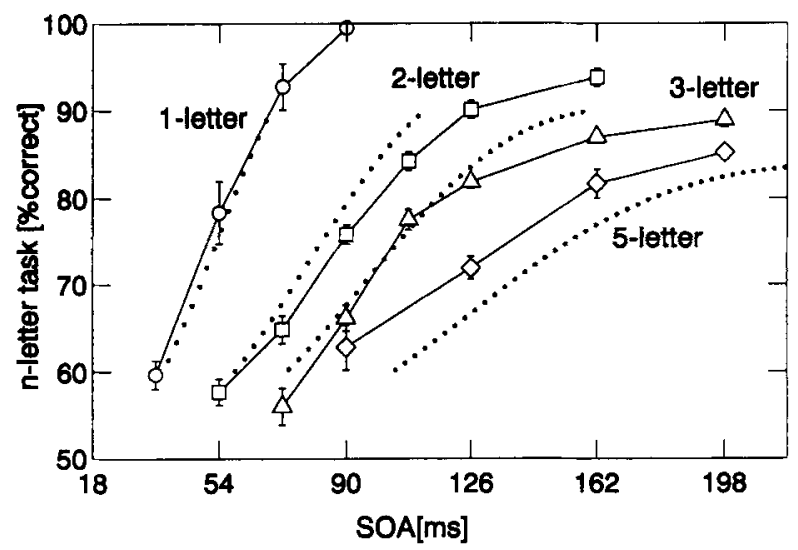

Figure 3. Display (schematic) and results of Experiment 1. (a) Schematic of stimulus (s) and mask displays (m) for one-letter, two-letter, and three-letter tasks (approximately central $4^{\circ} \times 4^{\circ}$ ) and for five-letter task (entire $14.5^{\circ} \times 14.5^{\circ}$ ). (b) Temporal sequence of stimulus and mask display. (c) Performance as a function of SOA, average, and standard error for 3 subjects. Dotted lines predicted by serial search with a rate of approximately 30 msec per letter. relative to the center of the display $\left(r=0\right.$ or 34 pixels, $\theta=0^{\circ}, 60^{\circ}$, $120^{\circ}, \ldots, 330^{\circ}$ ). Letter targets were T- or L-shaped and randomly oriented. Component lines of the $\mathrm{T}$ and $\mathrm{L}$ were 16 pixels long and 2 pixels wide, and the maximal luminosity was $100 \mathrm{~cd} / \mathrm{m}^{2}$, with lower values along the edges to reduce aliasing. The mask display consisted of one or more F-shaped elements. These mask elements were of identical dimensions and appeared at the same positions $(r, \theta)$ as the letter targets, but were oriented differently (Figure 3a).

In the one-letter task, a single letter target appeared and subjects responded with either "T" or "L." In the two-letter task, three-letter task, and five-letter task, two, three, and five letters appeared and subjects reported whether all letters were of the same type or whether one letter differed from the others. The possible responses were "same" or "different."

To quantify the resulting psychometric functions, the data were fit with a Weibull function (Weibull, 1951), which provided a better fit than an error function:

$$
P_{(\mathrm{SOA})}=50\left[1+\gamma_{n}\left(1-\exp \left(\frac{\mathrm{SOA}}{\alpha_{n}}\right)^{\beta}\right)\right] .
$$

Here, $n=1,2,3,5$ is the number of letters, and $\alpha_{n}, \beta$, and $\gamma_{n}$ are the threshold, slope at threshold, and ceiling performance, respectively. To reduce the number of free parameters, $\alpha_{n}$ and $\gamma_{n}$ were related to three parameters, $\alpha, \gamma$, and $\delta$ :

$$
\begin{gathered}
\gamma_{n}=1-\gamma(n-1), \\
\alpha_{1}=\alpha+\delta \quad \alpha_{2}=2.00 \alpha+\delta,
\end{gathered}
$$

and

$$
\alpha_{3}=2.67 \alpha+\delta \quad \alpha_{5}=3.90 \alpha+\delta
$$

The numerical factors were based on the assumption that letters are examined one at a time and in random order, and that the search terminates as soon as a second type of letter is encountered. In a serial search of this kind, an average number of 2.00, 2.67, and 3.90 letters needs to be examined to solve the two-letter, three-letter, and five-letter tasks, respectively. The remaining free parameters, $\alpha, \beta$, $\gamma$, and $\delta$, were fit with a least squares procedure to the performance data in Figure 3c.

Both presentation time and task type (letter number) were blocked. During one session, subjects proceeded systematically from higher to lower presentation times (SOAs) for one task type. Each subject devoted two or three sessions to each task type. Different subjects performed the tasks in different order: two-, three-, five-, one-, and two-letter tasks for Subjects C.C. and S.R.; one-, two-, three-, and five-letter tasks for Subject G.C. Each data point in Figure 3 is based on between 800 and 2,500 trials, with an average of approximately 1,600 trials per point. To control for practice effects, Subjects C.C. and S.R. performed the two-letter task both at the beginning and at the end of the experiment (which stretched over almost 2 months). No significant differences in performance were found.

\section{Results}

Performance of the one-, two-, three-, and five-letter tasks was established at several SOA values with 3 subjects (C.C., S.R., and G.C.; 32,300 trials total; Figure 3c). There were significant $(p<.005)$ differences in the performance of different tasks at the same SOA value, and of the same task at different SOA values (Student $t$ test). Differences between subjects, however, were significant only for 1 subject and only at two SOA values. Therefore, we chose to average performance of all subjects. The best fitting set of Weibull functions (Weibull, 1951) was found for $\alpha=$ $28 \mathrm{msec}, \beta=3.3, \gamma=0.1$, and $\delta=31 \mathrm{msec}(r=.97)$. 


\section{Discussion}

The outcome conforms well to that expected from a serial, self-terminated search. Each additional letter seems to require approximately $30 \mathrm{msec}$ additional processing time, as indicated by the parameter values $\alpha=$ $28 \mathrm{msec}$ and $\delta=30 \mathrm{msec}$. This shows that the letter task is similar to other $\mathrm{T} / \mathrm{L}$ search tasks, which have previously been found to involve serial search (Bergen \& Julesz, 1983; Kröse \& Julesz, 1989; Kwak \& Egeth, 1992; Moore, Egeth, Berglan, \& Luck, 1996).

The data seem to depart from those of the serial search model in one respect: When three or more letters are used, performance remains well below $100 \%$ even for long SOAs. We suspect that this is a consequence of the "fading" of visual persistence: The stimulus display is presented for only $36 \mathrm{msec}$, so subjects have to rely on visual persistence to examine the third, fourth, and fifth letters.

Of all four tasks, the five-letter task requires the longest SOA for a given level of performance: approximately $130-170 \mathrm{msec}$ for $70 \%-80 \%$ correct. This task was used in all subsequent experiments to engage the observer's attention.

\section{EXPERIMENT 2}

\section{Letter Task Engages Most, and Possibly All, of the Available Attention}

Here the five-letter task of the previous experiment (henceforth called simply "letter task") was combined with a probe task designed to be as undemanding as possible while still requiring attention. To quantify the extent to which the letter task engages attention, we established the AOC for this combination of tasks.

\section{Method}

Target and mask elements of the letter task were unchanged. A probe target (randomly oriented T or L, component lines 24 pixels long and 3 pixels wide, maximal luminosity $\approx 100 \mathrm{~cd} / \mathrm{m}^{2}$ ) appeared at a position $(r, \theta)$ with $r=4.3^{\circ}$ and $\theta$ random. The probe target was masked by a randomly oriented $\mathrm{F}$ of identical dimensions. The probe task consisted of identifying the probe target as either " $T$ " or "L" (Figure 4a).

Data were collected in blocks of 100 trials. Subjects received different instructions under the single- and the double-task conditions (see General Method). In the double-task condition, subjects were asked to vary the division of attention from block to block (while keeping it constant from trial to trial), favoring the letter task in some blocks, the probe task in other blocks, and neither task in yet other blocks. The order in which subjects responded to the two tasks was varied, but did not affect the outcome (not shown). In the two single-tasks conditions, subjects carried out only one of the two tasks.

The subjects for this experiment (C.H. and D.S.) were highly experienced and had previously participated for several weeks in concurrent-task experiments involving the letter task. In addition, each received three practice sessions prior to data collection. Subject C.H. performed eight sessions on the shorter and subsequently five sessions on the longer presentation time. Subject D.S. performed seven sessions on the longer and subsequently seven sessions on the shorter presentation time. In each session, subjects performed at least one block letter task (single) and one block probe task (sin- a

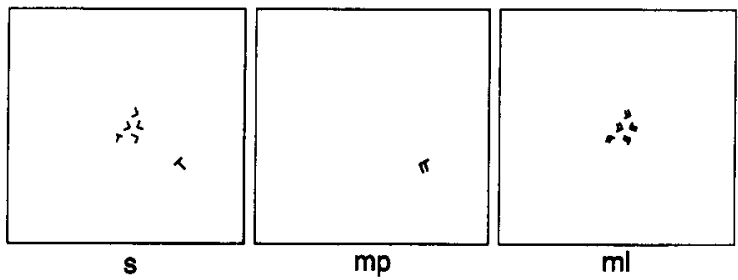

b

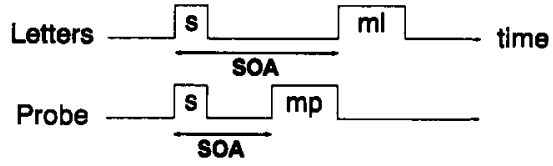

c

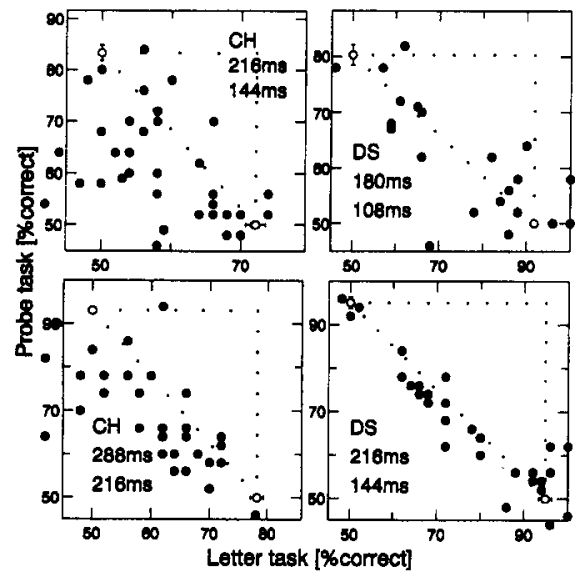

Figure 4. Display (schematic) and results of Experiment 2. (a) Schematic of stimulus (s), probe mask (mp), and letter mask (ml) displays. (b) Temporal sequence of the three displays. Letter and probe tasks have different SOAs. (c) Performance of each task as a function of performance of the other, shown separately for each subject and SOA. Labeling identifies subject, letter-task SOA, and probe-task SOA (from top). $\leftarrow O-$ denotes average and standard errors of single-task performance, and $\bullet$ denotes individual blocks of double-task performance.

gle), as well as several blocks of both letter and probe tasks (double task). Although the experiment lasted almost 2 months, singletask performance did not improve significantly over this period.

\section{Results}

Single-task and double-task performances of letter and probe tasks were determined for two SOA values with 2 subjects (C.H. and D.S., 11,700 trials total; Figure $4 \mathrm{c}$ ). The two SOA values were chosen to obtain singletask performances of $\approx 70 \%$ (shorter $\mathrm{SOA}$ ) and $\approx 90 \%$ (longer SOA).

In the double-task situation, the probability of success or failure in any given trial was slightly anticorrelated between the two tasks (i.e., a correct response to one task was accompanied more often by an incorrect response to the other task than would have been predicted by chance). The correlation was significant for Subject D.S. $(4,500$ 
trials, $\left.\chi^{2}=69.3, f=1, p<.005\right)$ and Subject C.H. $(7,200$ trials, $\chi^{2}=4.50, f=1, p<.05$ ). As a result of this correlation, probe-task performance was slightly lower in trials in which the letter response was correct and slightly higher in trials in which the letter response was incorrect (percentage correct $61.0 \%$ and $74.5 \%$, respectively, for Subject D.S., and $62.1 \%$ and $64.6 \%$, respectively, for Subject C.H.).

The performance level in any given block was strongly anticorrelated between the two tasks, as is evident from the scatter graphs in Figure 4c. When letter-task performance was at its best, probe-task performance was at or near chance, and vice versa. This correlation was significant for all subjects and SOA values (Kendall's $\tau=$ -0.39 to $-0.77, p<.0005$ ).

The compatibility index (see General Method) ranged from 0.14 to -0.25 , with a mean of $-0.03 \pm 0.05$ (see Table 2) and did not depart significantly from zero for any subject or SOA value.

Several other subjects performed the same tasks (e.g., M.G. and P.G.; 7,700 trials total) but received only one instruction, namely to give absolute priority to the letter task. For these subjects, probe-task performance was consistently near chance (results not shown).

During debriefing, subjects reported that they had been unable to simultaneously form clear impressions of both letter and probe targets, but that they had been able to voluntarily choose whether to form a clear impression of the one or the other. In addition, subjects reported that treating both tasks equally was more demanding than favoring one task over the other.

\section{Discussion}

The results show that letter- and probe-task performance are almost mutually exclusive: When one task is performed at or near its best, the other task is performed at or near chance. Subjects do produce intermediate outcomes when so instructed; that is, they can also perform both tasks below best but above chance. Together, these various outcomes determine the AOC of this combination of tasks.

The most striking feature of the AOC is its apparent linearity and symmetry: As the division of attention between letter and probe task varies, the respective performance levels of letter and probe tasks change by equal but opposite amounts. This implies that any division of attention that is of noticeable benefit to the probe task entails a noticeable decrease in letter-task performance. From this we can infer that the letter task, if performed at its best, engages most, and possibly all, of the attention that is available for this type of task.

A linear and symmetric AOC is consistent with the underlying PRFs (1) being identical for both tasks and (2) having a functional form of $f_{(\alpha)}$ with $f_{(\alpha)}=1-f_{(1-\alpha)}$, where $\alpha$ is the fraction of attention devoted to the task. It is not self-evident why the PRFs of two tasks would possess these properties and, as far as we know, no explanation has been advanced (Navon \& Gopher, 1979).

\section{EXPERIMENT 3 \\ Reducing Discriminability of Pop-Out Does Not Raise Attentional Cost}

In addition to performing the letter task, subjects located a target that popped out from the display. Discriminability of the pop-out was varied by changing the orientation difference between target and background elements. Current theories of attention (Navon \& Gopher, 1979; Norman \& Bobrow, 1975) predict that lowering signal strength should raise attentional cost. The present results did not bear out this prediction.

\section{Method}

Target and mask elements of the letter task were unchanged. The stimulus display (Figure 5) contained 242 Gabor elements on a hexagonal grid with 247 positions (nearest neighbor separation of 35 pixels). Five positions were occupied by letter targets. The luminance distribution of a Gabor element was given by

$$
f_{(x, y)}=\cos \left(2 \pi \frac{x \cos \theta-y \sin \theta}{\lambda}+\phi\right) \exp \left(-\frac{x^{2}+y^{2}}{2 \sigma^{2}}\right),
$$

where $\theta$ determines the orientation, $\lambda$ the spatial period, $\phi$ the phase, and $\sigma$ the size of the Gabor element; $f_{(x, y)}=0$ corresponded to a luminosity of approximately $50 \mathrm{~cd} / \mathrm{m}^{2}$ (background luminosity), and $f_{(x, y)}=1$ and $f_{(x, y)}=-1$ corresponded to approximately $100 \mathrm{~cd} / \mathrm{m}^{2}$ and approximately $30 \mathrm{~cd} / \mathrm{m}^{2}$, respectively (no gamma correction was used). The parameters used were $\lambda=14$ pixels, $\sigma=10$ pixels, and $\phi= \pm 90^{\circ}$ ( $\phi$ varied from element to element). Gabor orientation $\theta$ varied in steps of $5^{\circ}$.

The 241 Gabor elements of the background exhibited uniform orientation, either $77.5^{\circ}=90.0^{\circ}-12.5^{\circ}$ or $102.5^{\circ}=90.0^{\circ}+$ $12.5^{\circ}$, chosen randomly for every trial. The target element appeared at one of 24 array locations $(r, \theta)$, with $4.3^{\circ} \leq r \leq 4.5^{\circ}$ and $\theta$ chosen so that the target was at least $0.9^{\circ}$ above or below the horizontal midline. Thus the target of this experiment appeared at the same eccentricity as did the probe target in Experiment 2 . The target element differed from background elements in orientation by an amount that remained fixed during each block of trials and varied in the range of $15^{\circ} \leq \Delta \theta \leq 45^{\circ}$. The difference in orientation was either clockwise or counterclockwise, chosen randomly for every trial. The localization task consisted of reporting whether the target appeared in the "upper" or "lower" half of the display. This "crude" localization is essentially a detection task.

The first mask display contained 242 Gabor elements of varying orientation on a hexagonal grid with 247 positions (five positions remained empty; Figure 5). Gabor parameters were identical to those used in the stimulus display except that contrast was higher (luminosity ranged from $5 \mathrm{~cd} / \mathrm{m}^{2}$ to approximately $160 \mathrm{~cd} / \mathrm{m}^{2}$ ). The $\mathrm{sec}-$ ond mask display consisted of five F-shaped elements.

The use of Gabor elements was an important aspect of the design. This choice ensured that pop-out was based exclusively on the difference in orientation between target and background elements. Other types of texture elements (e.g., line elements) would have tended to form additional differences with respect to other featuresfor example, local luminance, spatial frequency, and emergent features formed by perceptual grouping (see, e.g., Julesz, 1984). This might have allowed the nature of the pop-out to change in the course of manipulations of attention and discriminability.

The critical range of orientation contrast between a peripheral target element and surrounding background elements is approximately $15^{\circ}-45^{\circ}$ (Nothdurft, 1991). Above $45^{\circ}$, localization performance changes little with onentation contrast. Below $15^{\circ}$, even prac- 


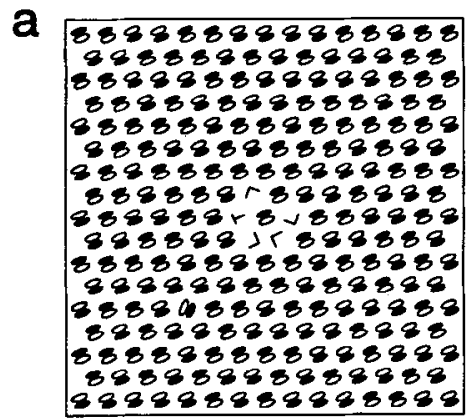

$\mathbf{s}$

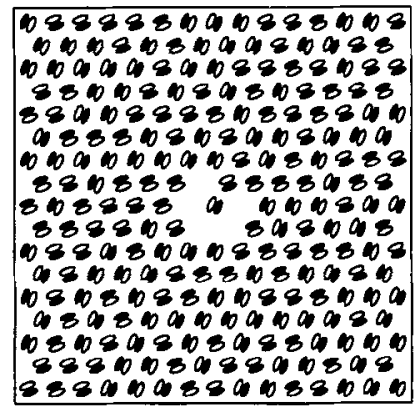

$\mathrm{mt}$

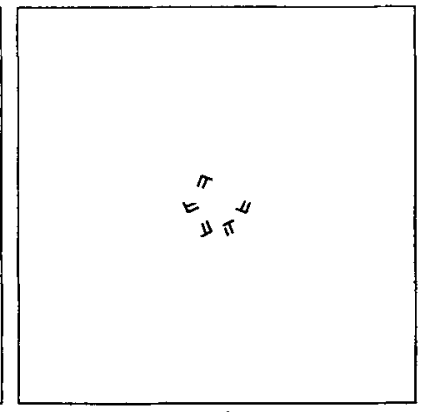

$\mathrm{ml}$

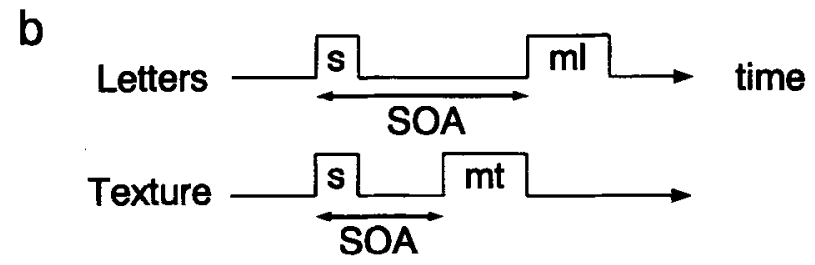

Figure 5. Displays of Experiment 3 (schematic). (a) Stimulus (s), texture mask (mt), and letter mask (ml) displays. Each Gabor element is represented by a black and a white ellipse placed side by side. In the actual stimulus, the localization target "pops out" (here it is in the lower-left quadrant of the display). (b) Temporal sequence of the three displays. Letter and localization tasks have different SOAs.

ticed observers are unable to localize the target with peripheral vision - that is, without resorting to eye movements. To obtain abovechance and below-ceiling performance throughout the critical range, we partially compensated for reduced orientation contrast by increasing SOA. As a result, task "difficulty" for different orientation contrasts had to be measured not only in terms of performance but also in terms of SOA.

Data were collected in blocks of 100 trials. In the single-task condition, subjects carried out either the letter task or the localization task. In the double-task condition, subjects carried out both tasks concurrently, giving priority to the letter task. In each session, subjects performed at least one block letter task and one block localization task, as well as several blocks of both letter and probe tasks. Each subject devoted between one and four sessions for each display (orientation difference $15^{\circ}-45^{\circ}$ ) and presentation time (SOA). No significant practice effects were observed during this small number of sessions.

\section{Results}

Single- and double-task performance of letter and localization tasks was determined for localization targets of different orientation contrast. Six subjects performed the tasks, sometimes at more than one SOA value (B.R., C.O., J.E., M.I., S.A., and S.T.; 20,700 trials; Figure 6). Different orientation contrasts resulted in dramatic differences in performance, as is evident from Table 1 and Figure 7. The smallest orientation contrast investigated $\left(\Delta \theta=15^{\circ}\right)$ is at the limit of visual sensitivity for orientation contrasts at $\approx 4^{\circ}$ of eccentricity (not shown; see also Nothdurft, 1991).

Single- and double-task performances were compared separately for each subject, $\Delta \theta$, and SOA (22 data sets, Student $t$ test). No significant difference was found in
$14 / 22(18 / 22)$ data sets for the localization task (letter task). A weakly significant $(p<.05)$ reduction in doubletask performance was found in $4 / 22(4 / 22)$ data sets. A significant $(p<.005)$ reduction in double-task performance of the localization task was found in $3 / 22$ data sets (Subject C.O., $\Delta \theta=45^{\circ}$, SOA $=54 \mathrm{msec}$; Subject M.I., $\Delta \theta=30^{\circ}, \mathrm{SOA}=54 \mathrm{msec}$; Subject S.T., $\Delta \theta=20^{\circ}$, $\mathrm{SOA}=180 \mathrm{msec}$ ) and a significant increase in $1 / 22$ data sets (Subject J.E., $\Delta \theta=15^{\circ}$, SOA $=270 \mathrm{msec}$ ).

The compatibility index varied considerably across subjects, ranging from 1.12 to 0.41 with a mean of $0.90 \pm$ 0.14 (Table 2). In 20/22 data sets, the compatibility index was significantly $(p<.0005)$ greater than zero, in $1 / 22$ data sets, the difference was significant $(p<.005)$, and in $1 / 22$ further data sets, the difference was weakly significant $(p<.05)$. However, there was no significant correlation between the compatibility index and orientation contrast (Kendall's $\tau$ ). The average compatibility index observed for Subjects B.R., C.O., J.E., M.I., S.A., and S.T. was $0.68 \pm 0.09,0.84 \pm 0.06,0.80 \pm 0.10,0.54 \pm 0.10$, $1.09 \pm 0.05$, and $0.88 \pm 0.07$, respectively.

In the double-task situation, no significant trial-bytrial correlation was found between the outcomes of letter and localization task for any data set, any $\Delta \theta$, or any subject ( $\chi^{2}$ measure of association). Significant block-byblock correlations were not observed either.

We summarize two additional experiments (stimuli and data not shown) in which the localization target was rendered salient by brightness or hue. For the localization of a bright target among less bright distractors (J.B. and S.R.; 5, 100 trials total; five data sets) and the local- 

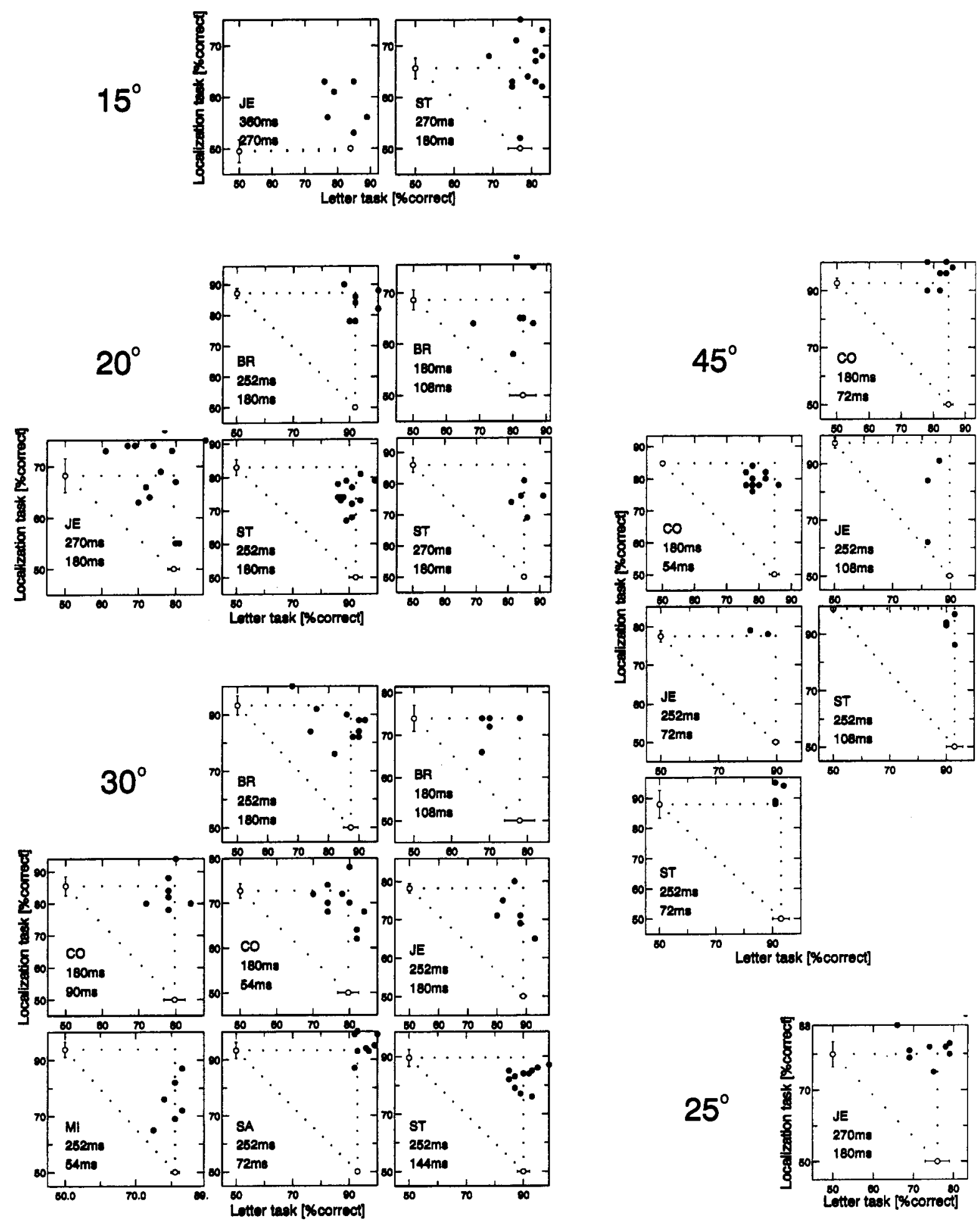

Figure 6. Results of Experiment 3. The orientation contrast of the localization target was $15^{\circ}, 20^{\circ}, 25^{\circ}, 30^{\circ}$, or $45^{\circ}$. Performance of the localization task as a function of performance of the letter task, and vice versa, shown separately for each subject and SOA. Labeling identifies subject, letter-task SOA, and localization-task SOA. $\vdash O-$ denotes average and standard errors of single-task performance, and $\bullet$ denotes individual blocks of double-task performance. 
Table 1

Performance and SOA of Visual Tasks

\begin{tabular}{|c|c|c|c|c|c|}
\hline \multirow[b]{2}{*}{ Type of Task } & \multicolumn{2}{|c|}{$\%$ Correct } & \multicolumn{2}{|c|}{ SOA (msec) } & \multirow[b]{2}{*}{ Data Sets } \\
\hline & $M$ & $S D$ & $M$ & $S D$ & \\
\hline - Letter task & 84.0 & 7.0 & 238 & 57 & 13 \\
\hline - Probe task & 87.5 & 5.5 & 138 & 38 & 6 \\
\hline Localization $15^{\circ}$ & 57.5 & 8.0 & 225 & 45 & 2 \\
\hline Localization $20^{\circ}$ & 78.5 & 8.5 & 166 & 29 & 5 \\
\hline Localization $25^{\circ}$ & 80.0 & 0.0 & 180 & 0 & 1 \\
\hline Localization $30^{\circ}$ & 85.0 & 8.5 & 115 & 50 & 8 \\
\hline Localization $45^{\circ}$ & 90.0 & 7.5 & 81 & 20 & 6 \\
\hline Sfmax (Braun, 1994b) & 84.1 & 3.4 & 98 & 13 & 16 \\
\hline - Sfmin (Braun, 1994b) & 84.8 & 2.9 & 133 & 24 & 13 \\
\hline Tilt discrimination $15^{\circ}$ & 90.5 & 6.5 & 94 & 26 & 10 \\
\hline Tilt discrimination $30^{\circ}$ & 83.0 & 5.5 & 81 & 27 & 2 \\
\hline Tilt discrimination $45^{\circ}$ & 86.5 & 6.0 & 118 & 22 & 11 \\
\hline Two weak hues & 75.5 & 5.0 & 90 & 18 & 4 \\
\hline Two strong hues & 93.5 & 4.0 & 72 & 0 & 4 \\
\hline One strong hue & 91.0 & 6.0 & 94 & 18 & 5 \\
\hline Two objects & 84.5 & 9.0 & 114 & 8 & 6 \\
\hline One object & 97.0 & 1.0 & 126 & 0 & 2 \\
\hline
\end{tabular}

Note-The $\cdot$ denotes tasks of high attentional cost (see Table 2).

ization of a chromatic target among isoluminous but achromatic distractors (E.R., S.R., and G.C.; 8,000 trials total; eight data sets); no significant differences between single- and double-task performance were observed in any data set.

During debriefing, subjects reported forming a clear impression of the targets of both letter and localization tasks. In addition, subjects reported being aware of attributes of the localization target other than location, such as orientation, contrast, and so on. The letter task was experienced as requiring more "effort" than the localization task even at low orientation contrast.

\section{Discussion}

The results show that a target that "pops out" from an otherwise uniform visual texture can be crudely localized even when attention is engaged elsewhere in the display. Localization performance is roughly comparable in single- and double-task situations, although double-task performance was somewhat lower than single-task performance in a minority of cases ( 7 of 22). Of course, some performance decrement is expected whenever two demanding tasks are performed concurrently (Allport, 1980; Duncan, 1980a; Pashler, 1994). Thus, a modest decrement does not necessarily imply a conflict over a specific resource such as attention, but may reflect factors other than attention - for example, having to maintain two sets of goals or having to encode two responses. The more telling aspect of the results would seem to be that some subjects (4 of 6) exhibited almost no decrement in localization performance (compatibility index $>0.8$ ). When the localization task involved a contrast in brightness or color (rather than orientation), an even more clear-cut outcome was obtained.

The most surprising result, however, is that the outcome does not depend on signal strength. The smallest orientation contrast investigated $\left(\Delta \theta=15^{\circ}\right)$ is at the limit of visual sensitivity for peripheral orientation contrasts (Nothdurft, 1991) and was correctly localized in only $\approx 60 \%$ of trials in spite of a presentation time of more than $200 \mathrm{msec}$. Localization of even smaller orientation contrasts $\left(\Delta \theta=10^{\circ}\right)$ was performed at chance even under conditions of continuous viewings (as long as the subject did not resort to eye movements). Accordingly, it would seem that target discriminability approaches zero near $\Delta \theta=15^{\circ}$. It is interesting to compare the localization task with the probe task in Experiment 3. In terms of performance and SOA, the localization task at $\Delta \theta=15^{\circ}$ is significantly more demanding than the probe task. Indeed, the probe task is comparable to the localization task at $\Delta \theta=25^{\circ}$ to $30^{\circ}$ ( Table 1). These considerations leave little doubt that localization and probe tasks place dramatically different demands on attention.

\section{EXPERIMENT 4 Discrimination of Pop-Out Orientation Entails Little Attentional Cost}

We explored the possibility that stimulus attributes other than presence and location can be reported "outside" the focus of attention. Subjects attempted to discriminate the orientation of a target that pops out in the visual periphery while focusing attention on the center of the display.

\section{Method}

Target and mask elements of the letter task remained unchanged. In addition, the display contained 89 Gabor elements on a hexagonal grid (Figure 8 ). These elements were larger and more widely spaced than were the Gabor elements in the previous experiment ( $\lambda=15$ pixels, $\sigma=14$ pixels, nearest neighbor separation of 50 pixels), and some elements near the center of the display were wholly or partly obscured by letter targets. Luminosity and contrast were the same as in the previous experiment. All Gabor elements except one exhibited approximately horizontal orientation, $\theta= \pm 2^{\circ}$ (background elements). The exceptional Gabor element (Gabor target) appeared at one of 18 array positions $(r, \theta)$ with $3.8^{\circ} \leq r \leq$ $4.3^{\circ}$ - that is, at approximately the same eccentricity as the peripheral targets in previous experiments, and was tilted either to the left or to the right of vertical $\left(\theta=90^{\circ}\right)$. Target orientations of either $\theta=$ $90^{\circ} \pm 15^{\circ}, \theta=90^{\circ} \pm 30^{\circ}$, or $\theta=90^{\circ} \pm 45^{\circ}$ were used in separate blocks of trials. The task (tilt discrimination) consisted of reporting

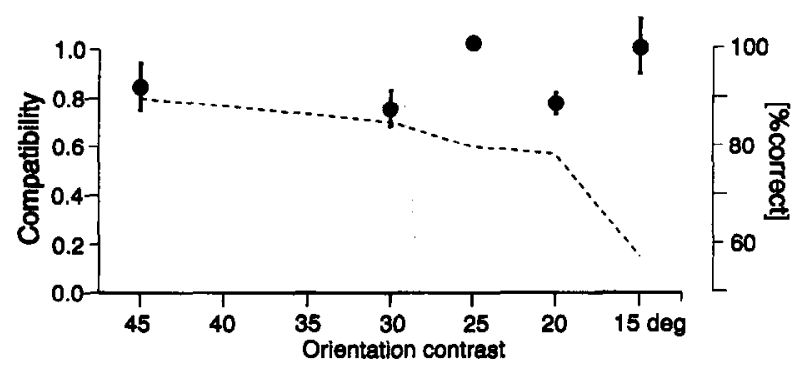

Figure 7. Summary of results of Experiment 3. Compatibility of letter and localization tasks (average and standard errors, $\vdash-1$ ) and single-task performance of localization task (dashed line) at $45^{\circ}, 3^{\circ}, 25^{\circ}, 20^{\circ}$, and $15^{\circ}$ orientation contrast. Target localization entails little or no attentional cost at all levels of task difficulty. 
Table 2

Compatibility Index for Various Task Combinations

\begin{tabular}{lcccc}
\hline \multicolumn{1}{c}{ Task Combination } & Range & $M$ & $S D$ & Data Sets \\
\hline Letter probe (no delay) & 0.14 to -0.25 & -0.03 & 0.05 & 4 \\
Letter \& localization $\left(15^{\circ}\right)$ & 1.12 & & 1.12 & 1 \\
Letter \& localization $\left(20^{\circ}\right)$ & 0.91 to 0.69 & 0.78 & 0.04 & 5 \\
Letter \& localization $\left(25^{\circ}\right)$ & 1.02 & & 1.02 & 1 \\
Letter \& localization $\left(30^{\circ}\right)$ & 1.09 to 0.41 & 0.76 & 0.07 & 8 \\
Letter \& localization $\left(45^{\circ}\right)$ & 1.06 to 0.45 & 0.84 & 0.09 & 6 \\
Letter \& tilt $\left(15^{\circ}\right)$ & 0.92 to 0.28 & 0.57 & 0.06 & 10 \\
Letter \& tilt $\left(30^{\circ}\right)$ & 0.90 to 0.63 & 0.77 & 0.13 & 2 \\
Letter \& tilt $\left(45^{\circ}\right)$ & 0.91 to 0.07 & 0.52 & 0.06 & 14 \\
Letter \& two weak hues & 1.05 to 0.62 & 0.84 & 0.18 & 4 \\
Letter \& two strong hues & 0.84 to 0.62 & 0.75 & 0.05 & 4 \\
Letter \& two objects & 1.03 to 0.62 & 0.83 & 0.10 & 6 \\
\hline
\end{tabular}

the approximate orientation of the Gabor target ("left" or "right" of vertical). We expected that performance would depend on the orientation difference between the two target alternatives $\left( \pm 15^{\circ}, \pm 30^{\circ}\right.$, or $\pm 45^{\circ}$ ), but this did not turn out to be the case.

The first mask display contained 89 elements on a hexagonal grid (some elements near the center of the display being partly or wholly erased; Figure 8). Mask elements consisted of two superimposed Gabor elements. One of these was oriented $\pm 2^{\circ}$, and the other was oriented $90^{\circ} \pm 15^{\circ}, 90^{\circ} \pm 30^{\circ}$, or $90^{\circ} \pm 45^{\circ}$, depending on target tilt in the stimulus display. Luminosity ranged from approximately $5 \mathrm{~cd} / \mathrm{m}^{2}$ to approximately $160 \mathrm{~cd} / \mathrm{m}^{2}$.

Data were collected in blocks of 100 trials. In the single-task condition, subjects carried out either the letter task or the tilt discrimination task. In the double-task condition, subjects carried out both tasks concurrently, giving priority to the letter task. In each session, subjects performed at least one block letter task and one block tilt discrimination, as well as several blocks of both letter task and tilt discrimination. Each subject devoted between one and four sessions for each display (target orientation $\pm 15^{\circ}, \pm 30^{\circ}$, and $\pm 45^{\circ}$ ) and presentation time (SOA). No significant practice effects were observed during this small number of sessions.

\section{Results}

Single- and double-task performance of letter task and tilt discrimination tasks was determined with 6 subjects, some of whom performed at more than one SOA value (B.E., D.A., G.A., J.O., M.I., and S.A.; 31,800 trials; Figure 9). In separate blocks of trials, target orientations of $\pm 15^{\circ}, \pm 30^{\circ}$, and $\pm 45^{\circ}$ resulted in average single-task performance/SOA of $91 \% / 94 \mathrm{msec}, 83 \% / 81 \mathrm{msec}$, and $87 \% / 118 \mathrm{msec}$, respectively (Table 1 ). Thus, all target orientations were about equally discriminable.

Single- and double-task performances were compared separately for each subject, target orientation, and SOA (26 data sets, Student $t$ test). No significant difference was found in 6/26 (19/26) data sets for the tilt discrimination (letter task). A weakly significant $(p<.05)$ reduction in double-task performance was found in $7 / 26$ $(5 / 26)$ data sets. A very significant $(p<.0005)$ reduction in double-task performance was found in $13 / 26$ (2/26) data sets. Of these latter data sets, $8 / 26(2 / 26)$ derived from 3 subjects (D.A., J.O., and M.I.).

The compatibility index varied substantially across subjects, ranging from 0.92 to 0.07 , with a mean of $0.62 \pm 0.10$ (Table 2). In 25 of 26 data sets, the compatibility index was very significantly $(p<.0005)$ greater than zero (the exception was subject B.E., $\Delta \theta=45^{\circ}$, $\mathrm{SOA}=126 \mathrm{msec}$ ). There was no significant correlation between the compatibility index and target orientation (Kendall's $\tau$ ). The average compatibility index observed by Subjects B.E., D.A., G.A., J.O., M.I., and S.A. was $0.18 \pm 0.05,0.51 \pm 0.05,0.63 \pm 0.05,0.31 \pm 0.01,0.49 \pm$ 0.04 , and $0.85 \pm 0.03$, respectively.

In the double-task situation, no significant trial-bytrial correlations were found between letter task and tilt discrimination responses for any data set, target orientation, or subject ( $\chi^{2}$ measure of association). No significant block-by-block correlations were found, either.

\section{Discussion}

The results show that the orientation of a salient stimulus in the visual periphery remains somewhat discriminable with attention focused on the center of the visual field, confirming subjects' reports with respect to subjective visual experience "outside" the focus of attention. However, the discriminability of orientation increases noticeably when the center of the visual field is ignored and attention becomes available. This dual-task

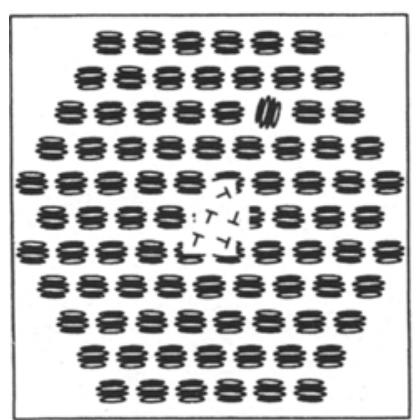

S

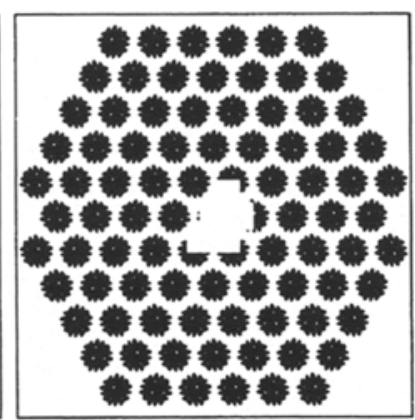

$\mathrm{mt}$

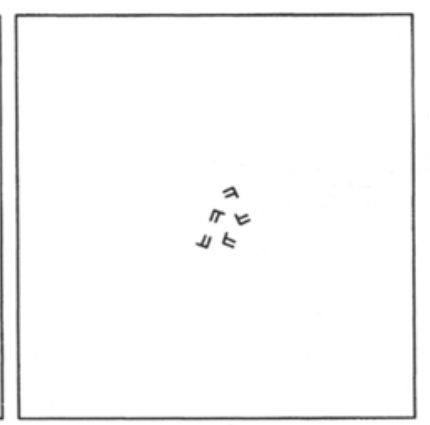

$\mathrm{ml}$

Figure 8. Displays of Experiment 4 (schematic): stimulus (s), texture mask (mt), and letter mask (ml) displays. Each Gabor element is represented by four ellipses, two black and two white, placed side by side. In the actual stimulus, the tilt discrimination target "pops out" (here it is in the upper-right quadrant of the display). The elements of the texture mask were generated by superimposing two Gabor elements. 

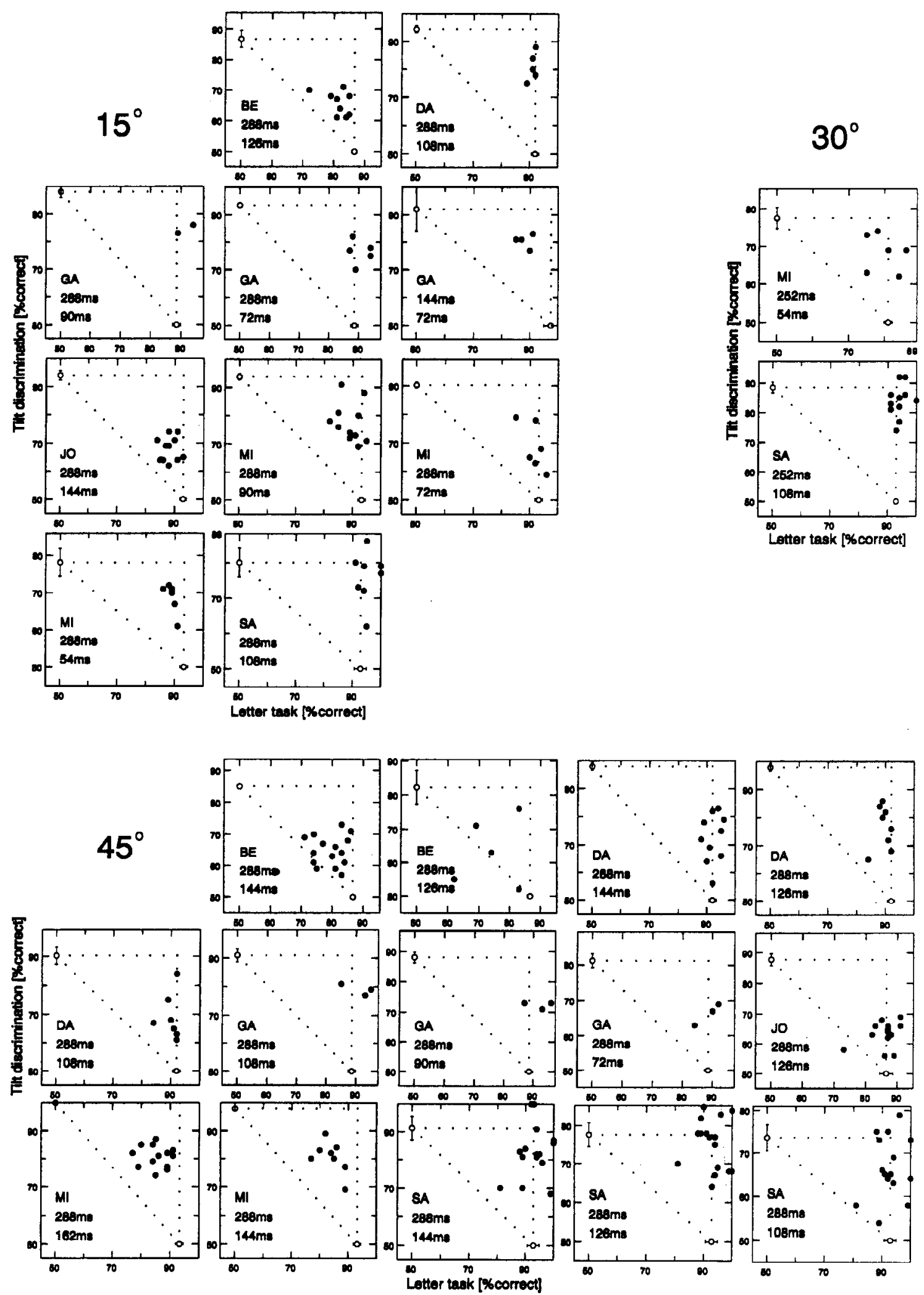

Figure 9. Results of Experiment 4. The orientation of the tilt discrimination target was $\pm 15^{\circ}, \pm 30^{\circ}$, or $\pm 45^{\circ}$ from vertical. Attention-operating characteristic ( $A O C$ ) for each subject and SOA. Labeling identifies the subject, letter-task SOA, and probetask SOA. $\mathrm{HO}-$ denotes average and standard errors of single-task performance, and $\bullet$ denotes individual blocks of doubletask performance. 
decrement seems too large and consistent to be explained solely by factors other than attention, such as the need to maintain two separate goals, and so on (Duncan, 1980a). Rather, it seems that there is a genuine difference in visual sensitivity $\left(d^{\prime}\right)$ for target tilt with and without attention. The absence of a negative correlation in the double-task situation suggests, however, that this residual performance does not place a strong demand on attention.

It seems surprising that discriminability is comparable for tilts of $\pm 15^{\circ}, \pm 30^{\circ}$, and $\pm 45^{\circ}$. Note, however, that the orientation difference distinguishing target and background $\left(75^{\circ} \pm 2^{\circ}, 60^{\circ} \pm 2^{\circ}\right.$, and $45^{\circ} \pm 2^{\circ}$, respectively) was large enough to let the target pop out from the display (see previous experiment). Thus it seems that target detection, rather than discrimination of target orientation, was the performance-limiting step. This assumption would also explain the results reported below with respect to hue discrimination.

\section{EXPERIMENT 5 \\ Discrimination of the Hues of Two Pop-Outs Entails Little or No Attentional Cost}

Subjects attempted to discriminate the respective hues of two targets that popped out in the visual periphery while focusing attention at the center of the display. Targets assumed one of four chromatic hues, calibrated to render targets equally salient as well as equally luminous. This ensured that discrimination performance would reflect the perception of hue, rather than of salience or luminosity.

\section{Method}

Nine isoluminous hues were used-more saturated pink, orange, turquoise, and green (stronger hues); less saturated pink, orange, turquoise, and green (weaker hues); and white. Hues were calibrated separately for each subject. Luminosity was matched to the white by flicker photometry. Salience was matched by measuring, for each hue, performance in the following "localization task": The stimulus display consisted of 247 disks on a hexagonal array (disk diameter of 20 pixels, center-to-center spacing of 35 pixels, luminosity approximately $50 \mathrm{~cd} / \mathrm{m}^{2}$, background luminosity approxi- mately $30 \mathrm{~cd} / \mathrm{m}^{2}$ ). One disk exhibited the hue in question (target), and all others were white. The mask display consisted of a similar array, except that more disks (33\%) exhibited the hue in question. The target element appeared at 1 of 24 array locations $(r, \theta)$, with $4.3^{\circ} \leq r \leq 4.5^{\circ}$ and $\theta$ chosen in such a way that the target was at least $0.9^{\circ}$ above or below the horizontal midline. Subjects reported whether the target appeared in the "upper" or "lower" half of the display. Localization performance was established at several SOA values, and the saturation of each hue was adjusted (without altering luminosity) until comparable psychometric curves were obtained for all stronger hues and (separately) all weaker hues.

In the main experiment (Figure 10), target and mask elements of the letter task were unchanged. The stimulus display contained the same array as the calibration experiment just described, except that five disks near the center of the display were obscured by letter targets, and two chromatic disks (upper and lower chromatic targets) appeared at positions $(r, \theta)$, with $4.3^{\circ} \leq r \leq 4.5^{\circ}$ and $\theta$ chosen in such a way that chromatic targets were at least $0.9^{\circ}$ above or below the horizontal midline. One chromatic target (pink or orange) appeared in the upper half, and another chromatic target (green or turquoise) appeared in the lower half of the display. The hue discrimination consisted of reporting the respective hues of the upper ("pink" or "orange") and lower ("green" or "turquoise") chromatic target.

The first mask display consisted of an array of 242 disks (five positions near the center remained empty). Thirty-three percent of the disks were pink, orange, green, or turquoise, and the remaining disks were white (Figure 10).

Data were collected in blocks of 100 trials. In the single-task condition, subjects carried out either the letter task or the hue discrimination. In the double-task condition, subjects carried out both tasks concurrently, giving priority to the letter task. In each session, subjects performed at least one block letter task and one block hue discrimination, as well as several blocks of both letter task and hue discrimination. Each subject devoted three sessions for each display for which data are reported (weak and strong hues). No significant performance improvement was observed between the first and the last sessions. Each subject had earlier received four practice sessions and, in addition, performed between four and eight sessions on similar displays for which data are not reported (see below)

Several variants of the experiment were conducted, all with similar outcomes, only one of which is reported below. Among the variants not reported was one in which only one chromatic target was used, and one in which both chromatic targets exhibited either an orange or pink hue. In yet another variant, subjects discriminated only the upper (lower) peripheral target. Because of the lengthy calibration procedure, only 2 subjects performed each variant.

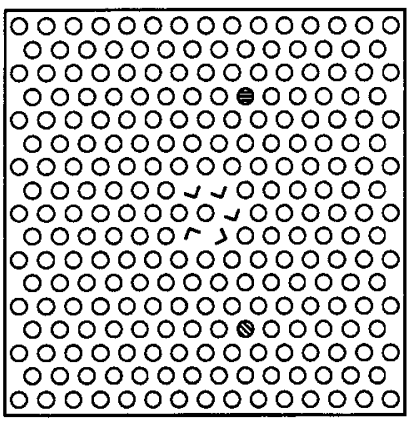

$\mathbf{s}$

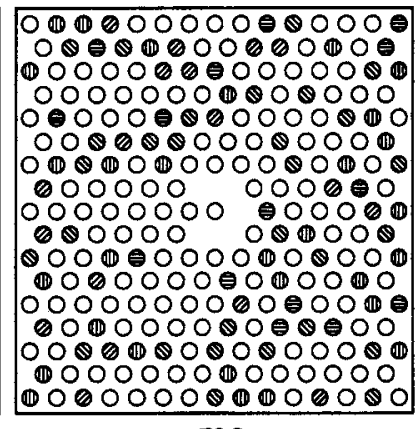

mc

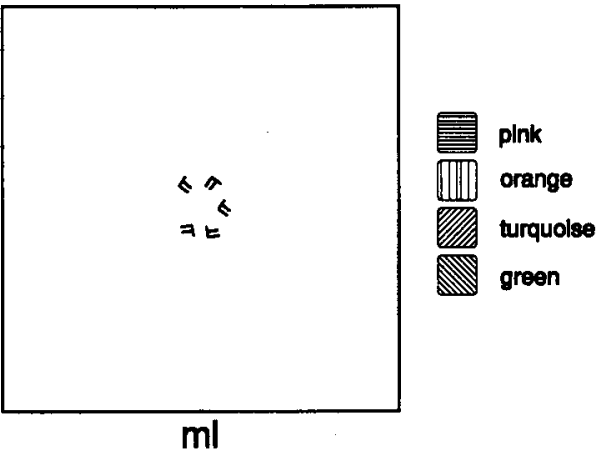

$\mathrm{ml}$

Figure 10. Displays of Experiment 5 (schematic): stimulus (s), color mask (mc), and letter mask (ml) displays. Hue is represented by hatching. In the actual stimulus, isoluminous white or chromatic disks appeared in a dark background. The stimulus contains five letter targets near the center of the display and one chromatic target each in the the upper and lower halves of the display. 


\section{Results}

Single- and double-task performances of letter and hue discrimination tasks were determined for stronger and weaker hues with 2 subjects (T.S. and L.N.; 7,100 trials; Figure 11). Average performance/SOA was $94.5 \%$ / $72 \mathrm{msec}$ for discriminating the stronger hues of two targets, and $91.0 \% / 94 \mathrm{msec}$ for discriminating the stronger hues of one target (Table 1). Average performance for discriminating the weaker hues of two targets was $76 \%$ / $90 \mathrm{msec}$.

Single- and double-task performances were compared separately for each subject and set of hues (four data sets, Student $t$ test). No significant differences were encountered in $3 / 4$ data sets. In $1 / 4$ data sets, double-task performance for hue discrimination was significantly $(p<.05)$ lower than single-task performance (Subject T.S., stronger hues).

The compatibility index was uniformly high, ranging from 1.05 to 0.62 , with a mean of $0.78 \pm 0.06$ (Table 2). In all four data sets, the compatibility index was significantly $(p<.0005)$ larger than zero. The average compatibility index for the upper and lower hue discrimination was $0.78 \pm 0.08$ and $0.80 \pm 0.09$, respectively. The average compatibility indices for Subjects L.N. and T.S. were $0.71 \pm 0.07$ and $0.86 \pm 0.16$, respectively.

In addition to discriminating the hues of two targets, we established psychometric functions for discriminating the hue of only one target (e.g., the one in the lower quadrant; T.S. and L.N.; 1,400 trials; four data sets). Performance for one and two targets was not significantly different at either of the two presentation times.

When asked about their experience in the double-task situation, subjects reported clearly perceiving the colors of both chromatic targets. No significant trial-by-trial or block-by-block correlations were observed between let- ter task and hue discrimination responses in the doubletask situation (not shown). Correlation data between upper and lower hue discriminations were not recorded.

\section{Discussion}

The results show that discriminating the hue of salient stimuli that pop out in the visual periphery entails little or no attentional cost. Performance improves only slightly when the center of the field is ignored and attention becomes available. It seems likely that this small increase can be attributed to factors other than attention, namely the intrinsic difficulty of encoding three responses (Duncan, 1980a). The failure to observe a significant anticorrelation in the respective performances of letter task and hue discrimination points to the same conclusion. The fact that the hues of two targets were discriminated just as reliably as the hue of one target suggests that hue discrimination was performed in parallel, consistent with the conclusion that hue discrimination in this display entailed little or no attentional cost. These results confirm subjects' subjective impression about their visual experience outside the focus of attention and support the notion of an ambient awareness that is independent of where and how attention is deployed.

\section{EXPERIMENT 6 \\ Discrimination of the Colors and Orientations of Two Pop-Outs Entails Little or No Attentional Cost}

Subjects attempted to discriminate the respective colors and orientations of two stimuli that popped out in the visual periphery while focusing attention at the center of the display.

\section{weaker hues}
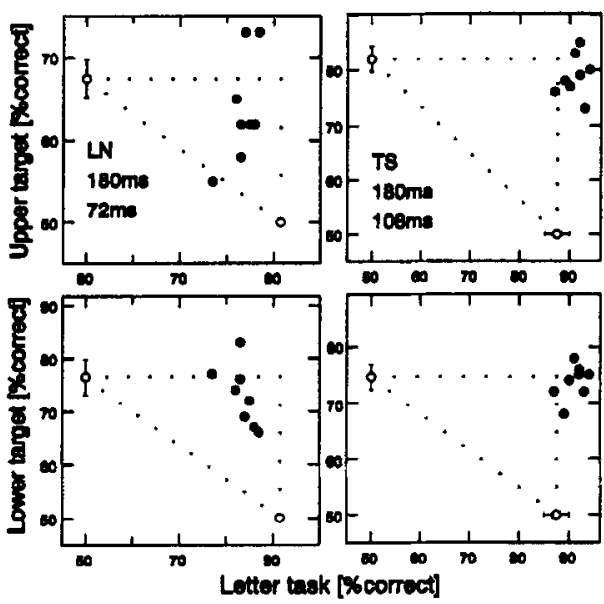

stronger hues

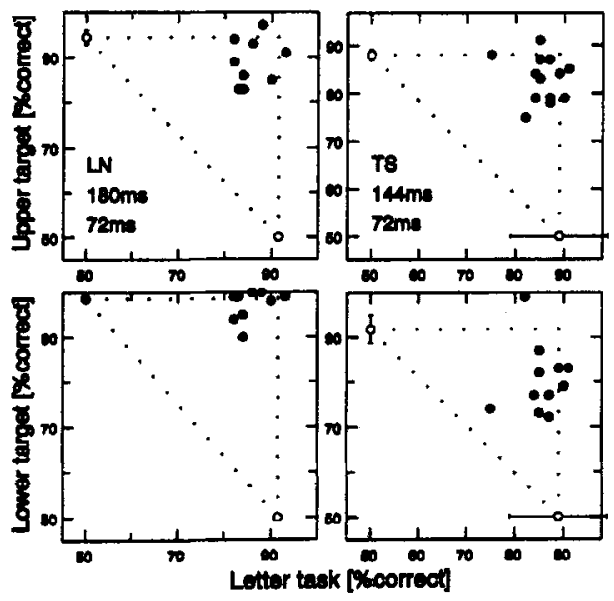

Figure 11. Results of Experiment 5. Two sets of pink, orange, turquoise, and green hues were used. "Weaker hues" were less saturated than were "stronger hues." Attention-operating characteristics (AOCs) for letter task and upper hue discrimination and for letter task and lower hue discrimination, separately for each subject and SOA. Labeling identifies the subject, letter-task SOA, and hue-discrimination SOA. $\vdash \mathrm{-}-$ denotes average and standard errors of single-task performance, and $\odot$ denotes individual blocks of double-task performance. 


\section{Method}

Target and mask elements of the letter task were unchanged. Upper and lower target objects appeared at positions $(r, \theta)$, with $r=4.3^{\circ}$ and $\theta$ chosen in such a way that objects were at least $0.9^{\circ}$ above or below the midline (Figure 12). Background luminosity was approximately $5 \mathrm{~cd} / \mathrm{m}^{2}$. Eight objects were used, distinguished by color (red, green, blue, and yellow) and orientation (horizontal and vertical). The four colors were isoluminous but not isosalient. The object-identification task consisted of reporting the respective color and orientation of the upper and lower target objects. To reduce the number of responses, subjects identified color and orientation by reporting the object's nickname ("poppies," "carrot," "wheat," "banana," "grass," "zucchini," "lake," or "eggplant"; see Figure 12).

The first mask display consisted of 18 mask elements arranged on a ring around the display center (radius of $4.3^{\circ}$; Figure 12). Two types of mask elements were formed by placing a red and a blue (a green and a yellow) object alongside each other. To minimize apparent motion between stimulus and mask displays, we used 18 mask elements (rather than two).

Data were collected in blocks of 100 trials. In the single-task condition, subjects carried out either the letter task or the object identification. In the double-task condition, subjects carried out both tasks concurrently, giving priority to the letter task. In each session, subjects performed at least one block letter task and one block object identification, as well as several blocks of both letter task and object identification. Each subject devoted between two and three sessions to the experiment. No significant performance improvement was observed between the first and the last session. Each subject had earlier received two practice sessions.

\section{Results}

Single- and double-task performances of letter- and object-identification tasks were determined with 3 subjects (J.O., M.I., and S.A.; 3,700 trials total; Figure 13). Object-identification performance was analyzed with respect to correct identifications of (1) both color and orientation, (2) orientation regardless of color, and (3) color regardless of orientation. No significant differences between single- and double-task performance of the letter task were found for 2 subjects, and a weakly significant $(p<.05)$ difference was found for the 3 rd (J.O.). No significant difference between single- and double-task performance of the object identification was found for 1 subject (M.I.), and a weakly significant $(p<.05)$ difference was found for another (S.A.). For the 3 rd subject (J.O.), there was insufficient double-task data to determine significance.

The compatibility index ranged from 1.03 to 0.62 , with a mean of $0.83 \pm 0.10$ (Table 2). For identifying orientation (regardless of color) and color (regardless of orientation), the mean compatibility indices were $0.83 \pm$ 0.09 , and $0.83 \pm 0.11$, respectively. For the upper and lower objects, the mean compatibility indices (color and orientation) were $0.90 \pm 0.06$ and $0.82 \pm 0.11$, respectively. Neither difference was significant. For Subjects J.O., M.I., and S.A., the mean compatibility indices were $0.63 \pm 0.04,0.87 \pm 0.03$, and $0.97 \pm 0.06$.

When asked about their experience in the triple-task situations, subjects reported forming a clear impression of the color and orientation of both target objects. No significant trial-by-trial or block-by-block correlations were observed. Correlations between upper and lower object responses were not recorded.

\section{Discussion}

Subjects successfully reported a total of four independent attributes of two peripheral stimuli while focusing attention at the center of the display. Although the reports were aided by memorized object names, the third response (lower object identification) tended to be less reliable than the second (upper object identification), a

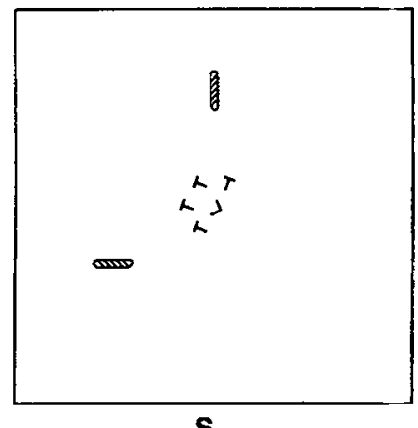

$\mathbf{S}$

b

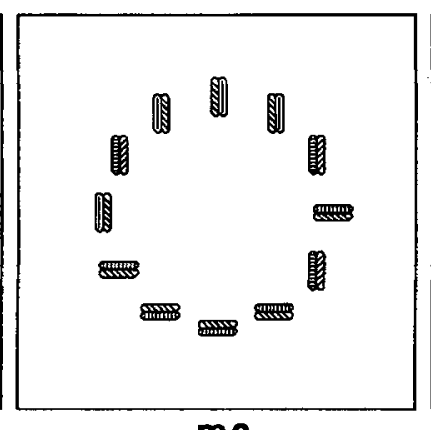

mc

carrot zucchini eggplent benena poppies grass lake wheat

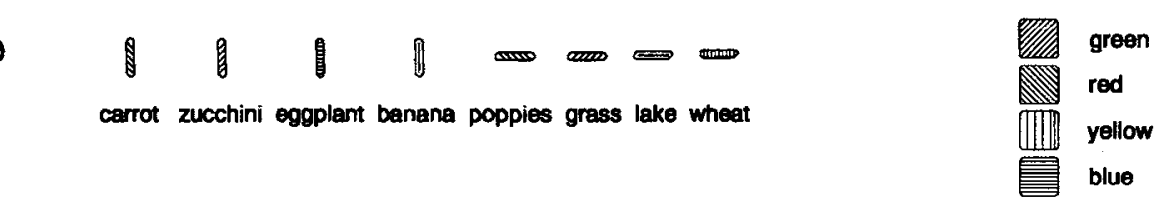

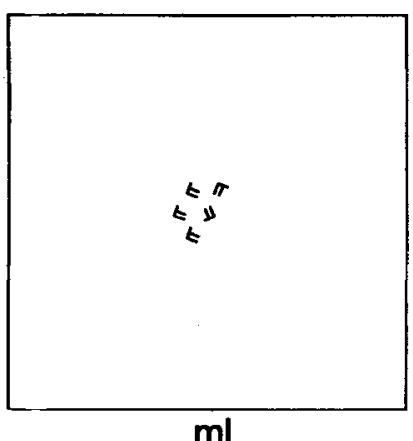

$\mathrm{ml}$

Figure 12. Displays of Experiment 6 (schematic). (a) Stimulus (s), color mask (mc), and letter mask (ml) displays. Hue is represented by hatching. In the actual stimulus, equiluminous upper and lower targets of the object discrimination task appeared in front of a black background. (b) Mnemonics used in the object-identification task (vertical targets are identified with vegetables, horizontal objects with nature scenes). 


\section{orientation} and color

\section{orientation}
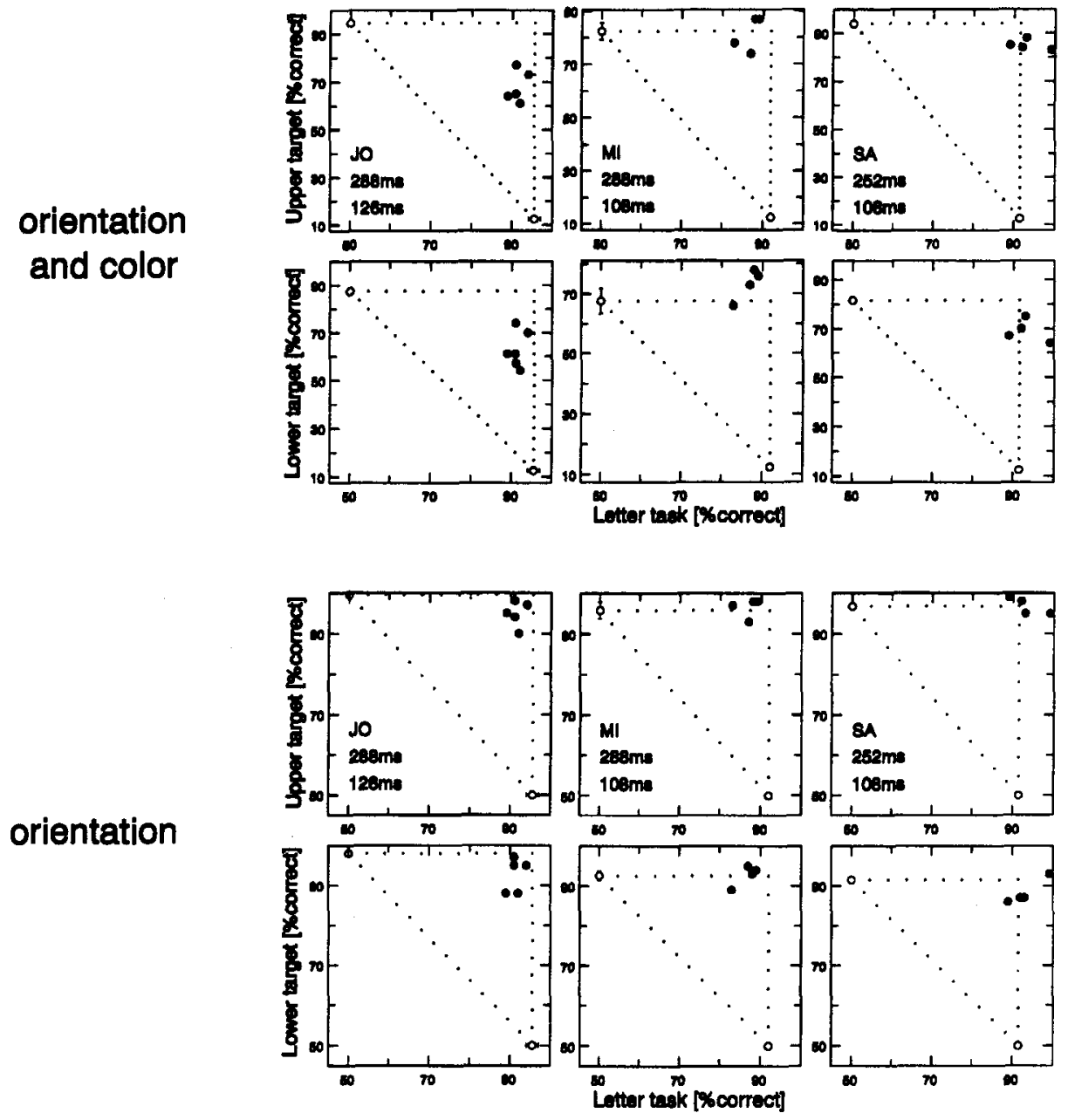

color
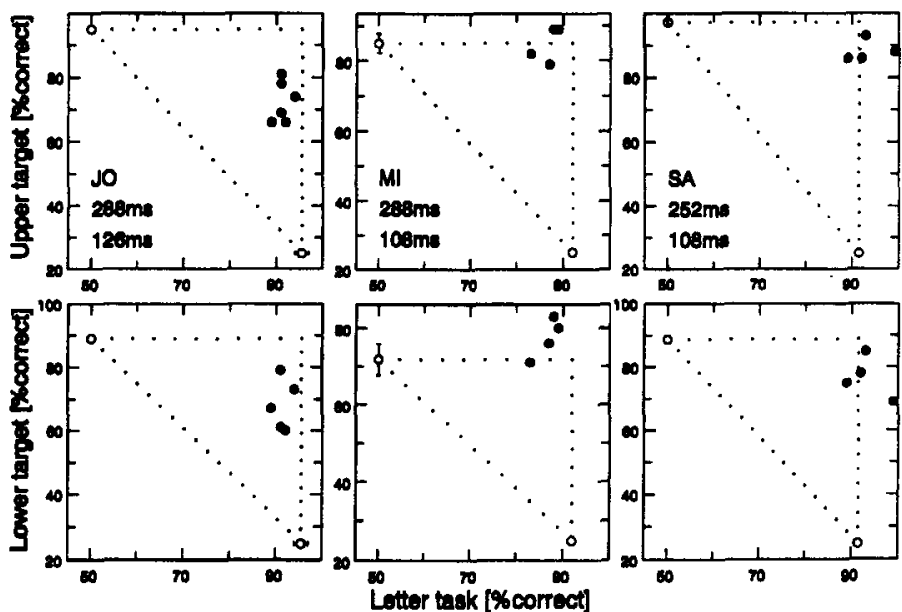

Figure 13. Results of Experiment 6. Two orientations (vertical and horizontal) and four colors (red, green, blue, yellow) were used. Object-identification performance was scored in several ways: percentage of correct identifications of both orientation and color, correct identification of orientation (regardless of color), and correct identification of color (regardless of orientation). Attention-operating characteristics (AOCs) shown separately for each subject and SOA. Labeling identifies the subject, lettertask SOA, and hue-discrimination SOA. HO- denotes average and standard errors of single-task performance, and $\bullet$ denotes individual blocks of double-task performance. 
perhaps because of a certain decay of short-term memory. Nevertheless, object-identification performance was comparable in the single- and double-task situations, and the small concurrent-task decrement obtained may well have derived from factors other than attention. The results further strengthen the notion that subjects enjoy an ambient awareness of visually salient stimuli and attributes (e.g., presence, location, color, and orientation) independently of where and how attention is deployed.

\section{GENERAL DISCUSSION}

We have introduced an improved concurrent-task paradigm to measure the attentional cost of detection and discrimination tasks. In spite of the demonstrated sensitivity of the paradigm, we find that a number of such tasks entail little or no attentional cost. Specifically, this seems to be true for tasks involving stimuli that pop out from the display and stimulus attributes that are relatively simple, such as position, color, and orientation. We hypothesize that competitive interactions at the level of early vision render certain stimuli and attributes visually salient, and that this salient information enters visual awareness independently of attention.

\section{Engaging Attention With a Concurrent Task}

Experiments 1-2 investigated the extent to which performance of the letter task would succeed in withdrawing attention from the periphery of the display. When performed at its best, the letter task appears to engage most or all of the available attention, since little or no attention seems to be left for a probe task, which is performed at chance. The outcome can be summarized in terms of our (inverse) measure of attentional cost, the compatibility index, which is essentially zero. Although we cannot conclude that no attention whatsoever remains for secondary tasks, we can conclude that what remains is too little to benefit the particular probe task we have used. Since the probe task was designed to be as undemanding as possible while still requiring attention, it seems that this cost is very small indeed. In sum, the evidence suggests that the letter task forces observers to focus attention almost entirely on the letter targets and to leave other parts of the display almost entirely unattended.

The only way to avoid this conclusion is to postulate the existence of different forms of attention. For example, one might suppose that letter discrimination engages one form of attention whereas color discrimination engages another, motion discrimination yet another, and so on. However, we know of no firm evidence that attention is "differentiated" (Sperling \& Dosher, 1986) in this way and that the concurrent discrimination of similar stimulus attributes poses a more severe conflict than that of dissimilar attributes. For example, Duncan (1993) found that conflict over attention depends not on the similarity or dissimilarity but simply on the number of the required discriminations. Among the present results, the lack of conflict between two similar discriminations in Experiments 5 and 6 constitutes two clear counterexamples. In addition, there are several examples of highly dissimilar tasks that severely conflict with one another (Braun, 1994b; Braun \& Koch, 1995; Wen, Koch, \& Braun, 1995).

In general, the undifferentiated nature of attention can be shown by demonstrating the transitivity of concurrenttask interference. For example, if two color discriminations interfere with each other, and two letter discriminations do the same, then the color and letter discriminations in question should also interfere with each other. More formally, if Task A interferes with Task B, and B interferes with Task $C$, then A should also interfere with $C$. Moreover, if A does not interfere with Task D, then B should also not interfere with $D$. In other words, it should be possible to sort tasks into nonoverlapping sets, with tasks that rely on attention forming one set and tasks that rely on pop-out forming another. Further experiments that test these predictions are currently under way.

\section{Attentional Cost of Detection Tasks}

Experiment 3 investigated the extent to which the detection $^{1}$ of pop-out requires attention. We used a wellknown pop-out situation involving a unique orientation in a dense array of oriented elements (Braun \& Sagi, 1990; Julesz, 1981; Nakayama \& Mackeben, 1989; Nothdurft, 1991; Sagi, 1990; Sagi \& Julesz, 1985). When pop-out was detected as a secondary task with the letter task as a primary task, detection performance remained far better than chance. Indeed, performance was comparable with and without the primary task; that is, it was comparable with attention fully available and with attention heavily engaged elsewhere. The modest performance difference exhibited by some subjects would seem to be attributable to factors other than attention. In a concurrent-task situation, subjects need to maintain two sets of goals and encode two responses, and this is expected to reduce performance somewhat compared with when each task is carried out alone (Allport, 1980; Duncan, 1980a; Pashler, 1994).

This interpretation is strengthened by the most surprising aspect of these results - namely, that the (small) concurrent-task decrement does not grow as the discriminability of pop-out is reduced. We varied the orientation difference between target and background elements from $45^{\circ}$, where discriminability is high $\left(d^{\prime} \approx 1.8\right.$ at $\mathrm{SOA} \approx$ $80 \mathrm{msec})$, to $15^{\circ}$, where discriminability is marginal $\left(d^{\prime} \approx\right.$ 0.3 at $\mathrm{SOA} \approx 225 \mathrm{msec}$ ). Throughout this range, detection performance remained comparable with and without the primary task. This is illustrated in Figure 7, which shows that the compatibility index for the combination of letter and pop-out detection tasks is uniformly high. If the attentional cost had been masked because performance was "data limited" for highly discriminable pop-out, then attentional cost should have increased as performance became "resource limited" for marginally discriminable pop-out (Navon \& Gopher, 1979; Norman \& Bobrow, 
1975). The fact that no such increase was observed suggests that the attentional cost of pop-out detection was effectively zero.

However, we do not claim that the attentional cost of pop-out detection is exactly zero. What we can say is that, having applied the most sensitive paradigms currently available, we did not find unambiguous evidence for such a cost. In any case, the difference between "exactly" zero and "effectively" zero is small from a practical point of view: In either case significant visual capabilities are independent of where and how the bulk of attention is deployed.

\section{Influence of Distractors}

It is instructive to contrast the present results with those of another study employing the same concurrenttask paradigm (Braun, 1994b). In the present experiment, only one element popped out from the display, whereas in Braun (1994b) there were several such elements. One of these elements was the target of a visual search task, and the others were distractors. The aim of the study was to determine how the attentional cost of visual search is influenced by the presence and nature of distractors.

Target and distractors differed with respect to size, luminance, chromaticity, or pattern, and, as a result, also differed in their respective intrinsic detectability. ${ }^{2}$ Two types of situations were investigated: (1) The target element was intrinsically more detectable than the distractor elements, and (2) the target element was intrinsically less detectable than the distractor elements. This is illustrated in Figure 14.

In general, the two types of situations just mentioned are known to give rise to search asymmetries (Treisman \& Gormican, 1988; Treisman \& Souther, 1985) in the sense that visual search tends to be more difficult when the target is intrinsically less, rather than more, detectable than the distractors. In the study at issue (Braun, 1994b), however, search performance was comparable in a

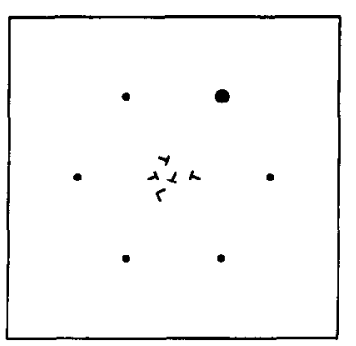

b

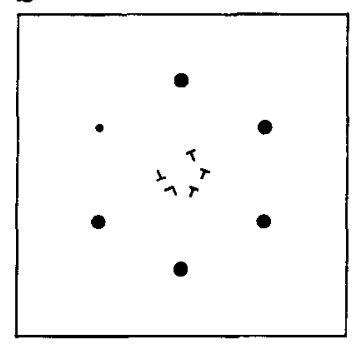

Figure 14. Examples of displays used by Braun (1994a). In general, subjects are asked to perform the letter task and to carry out a visual search among six peripheral stimuli. The target of the search differs from the distractors in size, brightness, color, or pattern. In the example shown, the target is (a) larger than the distractors or (b) smaller than the distractors. Displays were presented briefly and masked, and the SOA was adjusted to obtain comparable performance on both types of visual search in the single-task situation. However, concurrent performance of the letter task revealed that the two types of visual search entail dramatically different attentional costs. both types of situations, at least as long as attention was fully available. In other words, no search asymmetry was evident in single-task performance. However, a dramatic search asymmetry was obtained in the concurrent-task situation - that is, when attention was engaged by the primary task and visual search was the secondary task. Search performance collapsed to near-chance level for targets that were intrinsically less detectable than the distractors, but remained at or near its single-task level for targets that were intrinsically more detectable than the distractors.

In sum, the attentional cost of detection in a general situation (i.e., visual search) depends not only on the targetto-be-detected but also on the presence and nature of other stimuli in the display; that is, it depends on context. Specifically, attentional cost does not depend on the absolute level of target detectability but on the relative level of the intrinsic detectabilities of target and potential distractors, respectively. This pattern of results strongly suggests that attentional cost is governed by competition among the various stimuli in a display.

\section{Competition for Saliency}

Competition between stimuli is not a new idea and has long been postulated to account for "visual saliency." In one influential model (Koch \& Ullman, 1985), a stimulus must "win" a competition with other stimuli in the display in order to become visually salient. As a result, visual saliency depends as much on other stimuli in the display-that is, on context-as on the salient stimulus itself. Further evidence for a competition for saliency comes from the behavioral effects of cortical and subcortical lesions in nonhuman primates: Stimulus detection in the visual region affected by the lesion tends to be impaired only if other stimuli are present outside this region (Desimone, 1992; Desimone \& Duncan, 1995; Robinson \& Petersen, 1992; Schiller \& Lee, 1991). A similar phenomenon is sometimes observed in humans after parietal injury ("extinction"; Bisiach \& Vallar, 1988; Kinsbourne, 1993).

From a theoretical point of view, there seems to be a consensus that visual saliency depends largely on stimulus factors and is the result of three levels of parallel processing: (1) Feature-selective filters register visual information in parallel across the visual field ("feature maps"; Koch \& Ullman, 1985; Treisman, 1988, 1993; Wolfe, 1994); (2) lateral inhibition of limited spatial range enhances singularities and discontinuities in the distribution of features (Malik \& Perona, 1990; Nakayama, 1991; Nothdurft, 1990; Rubenstein \& Sagi, 1990; Sagi, 1990; Sagi \& Julesz, 1987); and (3) competitive interactions of larger spatial range further enhance the strongest singularities and discontinuities in the visual field (the "saliency map" of Koch \& Ullman, 1985; the "master map" of Treisman, 1988, 1993; see also Desimone \& Duncan, 1995).

Taken together with the present results, these findings suggest that the attentional cost of detection depends on the outcome of a competition for visual saliency among the various stimuli in the display. Specifically, attentional 
cost will depend on whether the stimulus to be detected "wins" or "loses" the competition for saliency among the various stimuli in the display. "Winners" enter ambient visual awareness and thus are detected at essentially no attentional cost. "Losers" are barred from ambient awareness and thus are detected only when attention is not otherwise engaged. A related prediction is that the presence of distractors will be felt most keenly when attention is somehow compromised - for example, as the result of a lesion or of performing a concurrent task (Braun, 1994b; Schiller \& Lee, 1991). When attention is functioning normally and is freely available, the presence of distractors will be of little consequence.

\section{Attentional Cost of Discrimination Tasks}

Our results on the attentional cost of discriminating various attributes of stimuli that pop out from a display are summarized in Figure 15. Whereas discrimination of letter shape requires essentially full attention (compatibility with letter task $\approx 0.0$ ), discrimination of triangular and circular shape (Braun, 1994b), discrimination of orientation, and discrimination of color are significantly less demanding of attention (compatibility $=0.4-0.8$ ). These results confirm the widely held notion that discrimination of some stimulus attributes is more costly in terms of attention than that of others (see, e.g., Cheal \& Lyon, 1994; Julesz, 1984; Treisman \& Gormican, 1988). We note that among the attributes investigated, only the discrimination of letter shape requires full attention. It is probably no coincidence that this is also the one attribute that does not pop out in a visual search situation and is not thought to be processed at the level of early vision (Bergen \& Julesz, 1983; Kröse \& Julesz, 1989). All other investigated attributes, including triangular and circular shape, do pop out in a visual search situation and are thought to be processed by early vision (Julesz, 1981, 1984, 1991).

Accordingly, we predict that only the discrimination of attributes that are not processed in parallel at the level of early vision requires full attention. Attributes that are processed by early vision should be discriminable with

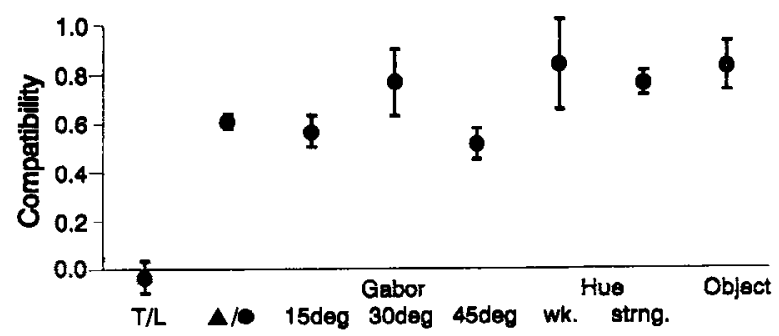

Figure 15. Summary of concurrent task results on discrimination tasks. Compatibility with letter task (average and standard errors, $|-|)$ as a measure of the attentional cost of various discrimination tasks, all involving salient stimuli. From left, discrimination of letter shape (Experiment 2), triangle/circle (Braun, 1994b), orientation (Experiment 4), hue of two targets (Experiment 5), and color and orientation of two targets (Experiment 6). All attributes except letter shape are significantly discriminable "outside" the focus of attention. little or no attention. This seems to be the case for hue discrimination, which is performed almost as well with a concurrent task as without a concurrent task (compatibility $\approx 0.8$ ). In fact, the performance decrement for hue discrimination is comparable to that observed with detection tasks (compatibility $\approx 0.8-1.0$; see Figure 7 ), and thus may well be due to the intrinsic difficulty of the concurrent-task situation rather than to a conflict over attention (Allport, 1980; Duncan, 1980a; Pashler, 1994).

Lack of attention may result in a partial loss of discriminability if multiple "signals" are relevant to a discrimination but only some of these fall into the domain of early vision (e.g., signals sensitive to orientation and complex shape, respectively). In this case, withdrawal of attention will leave the observer to respond on the basis of fewer signals and thus will reduce performance without eliminating it entirely. This may be the case for the discrimination of orientation in Experiment 4, which exhibited an intermediate attentional cost.

We again emphasize that these predictions apply only to attributes of stimuli that pop out from the display. If pop-out is compromised by the presence of other prominent stimuli in the display, attentional costs may be significantly higher. In addition, there may well be other factors that influence discriminability of unattended stimuli that are not yet fully understood. A case in point is orientation discrimination, which under some conditions exhibits a small attentional cost (compatibility $\approx 0.8$ in Experiment 6 ), under others an intermediate attentional cost (compatibility $\approx 0.5-0.8$ in Experiment 4 ), and under yet other conditions a large attentional cost (Braun \& Sagi, 1990; Sagi \& Julesz, 1985).

One factor that may account for this dramatic difference in attentional cost is target size, since in the studies in question attentional cost increased with decreasing target size. ${ }^{3}$ Perhaps early vision produces a coarser representation of the visual field than attentive vision, so that only the orientation of relatively large stimuli can be discriminated without attention. Another important factor is the presence and nature of stimuli near the target. In Experiment 6 and in Braun and Sagi (1990), there were no such stimuli, whereas in Experiment 4 and in Sagi and Julesz (1985) the target was embedded in a uniform background array. If the margins of a background array are visually salient themselves, as seems likely, then the different outcomes of Experiment 4 and Sagi and Julesz (1985) could be due to the fact that in Sagi and Julesz, the target was much farther from the array margin than in Experiment 4. However, the difference between Experiment 6 and Braun and Sagi cannot be explained in this way. We are currently trying to clarify these issues by comparing orientation discrimination thresholds in the presence and absence of attention for sinusoidal gratings of different spatial frequencies and luminance contrasts (Wen, Koch, \& Braun, 1996).

Another interesting aspect of our results is that subjects discriminated two distinct stimuli outside the focus of attention. At first glance, this may seem at odds with the notion of a competition for saliency, since it implies 
that two stimuli are visually salient at the same time. However, this is exactly what one would expect if the perceptual function of the competition for saliency is to provide an ambient awareness of the visual environment. Only in the context of guiding eye movements or shifting the focus of attention is there a need to determine a single, most salient location. Accordingly, we propose that the competition for saliency admits multiple winners, rather than the single winner proposed previously (Koch \& Ullman, 1985), and that the number of winners is limited by the spatial range of the underlying interactions.

The fact that subjects discriminate two distinct stimuli with little or no attention further suggests that early vision is capable of solving at least a mild instance of the "binding problem" (Damasio, 1987; Rummelhart \& McClelland, 1986). Neuronal populations in different visual cortical areas exhibit significantly different response properties (see, e.g., Felleman \& Van Essen, 1990; Van Essen \& Gallant, 1994), so different attributes of the same stimulus are to some extent represented by activity at anatomically distinct sites. It has been proposed that focal attention is needed to reassemble the various attributes into a perceptual unit, namely, into one visual object ("featureintegration theory," Treisman, 1988, 1993; Treisman \& Gelade, 1980). The present results suggest that this is not strictly true, and that early vision is able to associate attributes such as color and orientation with the correct stimulus even when there is a second stimulus at a distant visual location. Indeed, visual search studies provide some converging evidence for this possibility (Mordkoff, Yantis, \& Egeth, 1990; Pashler, 1987).

\section{Other Concurrent-Task Studies}

Taken together, our results suggest that the attentional cost of simple visual tasks depends on two factors, both equally important: (1) the task-relevant stimulus must be visually salient; that is, it must be intrinsically not less detectable than other prominent stimuli in the visual field, and (2) the task-relevant attribute must be processed in parallel at the level of early vision. If both conditions are met, the task entails little or no attentional cost, and its performance is largely independent of where and how attention is deployed. If one or both conditions fail to be met, the task requires full attention. Intermediate outcomes are obtained when early vision processes the task-relevant attribute less completely than attentional vision, as seems to be the case for orientation. It follows that attentional cost depends neither on the nature of the task - that is, on whether it involves detection or discrimination-nor on the absolute level of performance, that is, on discriminability $d^{\prime}$.

When one surveys the dual-task literature, one finds very little evidence at variance with these predictions. Several dual-task studies of the discrimination of letter shape have encountered substantial dual-task penalties, consistent with a significant attentional cost of of this kind of discrimination (Duncan, 1984; Duncan et al., 1994; Sperling \& Melchner, 1978). In a widely noted study, Duncan (1980b) encountered significant dual-task penalties for the discrimination of attributes of similar complexity. A more recent set of dual-task studies has investigated discrimination of line length (Bonnel \& Miller, 1994; Bonnel, Possamai, \& Schmitt, 1987). Specifically, a pair of parallel and closely spaced lines was presented on either side of fixation, and subjects discriminated small differences in length within each pair. This would appear to be a case in which discrimination may be based on several redundant features, only some processed at the level of early vision. Indeed, a significant dual-task penalty was observed.

A similar study was carried out with respect to detection or discrimination of luminance increments or decrements (Bonnel et al., 1994). No dual-task peralty was found for independent detection of two luminance increments, consistent with automatic and effortless processing of luminance increments by early vision (see, e.g., Julesz, 1981; Shaw, 1984). However, there was a dual-task penalty for independent discrimination of luminance increments and decrements, an outcome interpreted by the authors in terms of altered task requirements (discrimination vs. detection) rather than in terms of altered physical stimulation (decrements vs. increments). However, it seems quite possible that early vision is differentially sensitive to luminance increments and decrements (see, e.g., Bashinski \& Bacharach, 1980). This interpretation is strengthened by the observation that the attentional cost of visual search rises dramatically if negative-contrast target and distractors are used instead of their positivecontrast equivalents (Braun, 1996). This is clearly an issue that deserves further study.

\section{Neural Basis}

The notion that competitive interactions select information that is perceived independently of attention fits well with recent findings of primate neurophysiology. Throughout visual cortex, neuronal responses to a preferred stimulus tend to be inhibited by the presence of similar stimuli nearby (Allman, Miezin, \& McGuinness, 1985; Desimone, Schein, Moran, \& Ungerleider, 1985; Knierim \& Van Essen, 1992; W. A. Press, Knierim, \& Van Essen, 1994). This surround inhibition between similar stimuli is generally thought to contribute to visual saliency and pop-out (Desimone \& Duncan, 1995; Koch \& Ullman, 1985; Nakayama, 1991; Robinson \& Petersen, 1992). Presumably, this inhibition attenuates neuronal responses to all stimuli except those with odd or unusual attributes not shared by other stimuli nearby. Global competition, for which there is some evidence in inferotemporal cortex (Miller, Gochin, \& Gross, 1993; Sato, 1995), could further inhibit neuronal responses until only the most prominent stimuli in the visual field-those that are visually salient and pop out-elicit a strong neuronal response (Desimone \& Duncan, 1995; Koch \& U11man, 1985). This would be consistent with a recent report that visual cortical responses to complex visual scenes are surprisingly few and far between (Gallant, Connor, \& Van Essen, 1994). Accordingly, visual experience outside the attentional focus may simply be determined by the 
strength of neuronal responses after surround inhibition and global competition have taken effect.

Inside the attentional focus, neuronal responses are likely to be governed by a different set of rules. It is known that attention modulates neuronal responses at almost all cortical levels (Desimone \& Duncan, 1995; Maunsell, 1995). In cortical areas V2, V3, and V4, as well as in inferotemperal cortex, visual responses to a stimulus are stronger (in up to half the neurons) when the stimulus is relevant to behavior than when the stimulus is viewed passively (Chelazzi, Miller, Duncan, \& Desimone, 1993; Haenny, Maunsell, \& Schiller, 1988; Maunsell, 1995; Moran \& Desimone, 1985; Motter, 1994; Spitzer, Desimone, \& Moran, 1988). A puzzling aspect of these results is that the attentional effect is often rather small. More robust effects seem to be obtained only when the task-relevant stimulus is joined by task-irrelevant stimuli nearby (Moran \& Desimone, 1985; Motter, 1993; Reynolds, Chelazzi, Luck, \& Desimone, 1994; Reynolds, Nicholas, Chelazzi, \& Desimone, 1995). Indeed, with a dense array of many similar stimuli, attentional modulation of neuronal responses can be demonstrated even in area Vl (Motter, 1993; W. A. Press et al., 1994).

The apparent correlation between the size of attentional effects and the presence of "competing" stimuli has not escaped notice (Desimone \& Duncan, 1995; Motter, 1993). Perhaps attention modulates neuronal responses mostly indirectly, by suppressing surround inhibition and global competition at the attended location. In this way attention could "protect" (Reynolds et al., 1995) the response to attended stimuli from the inhibitory influence of unattended stimuli. The possibility that attention suppresses surround inhibition and global competition is consistent with the psychophysical finding that stimulus competition is weaker in attended than in unattended parts of the visual field (Braun, 1994b).

\section{Conclusion}

We have used a sensitive concurrent-task paradigm to investigate what determines the attentional cost of detection and search tasks. To test the importance of discriminability $d^{\prime}$, we varied target contrast over a large range while maintaining the target at a competitive advantage with respect to other stimuli in the display. We observed no change in attentional cost. In a complementary study (Braun, 1994b), we placed the target at either a competitive advantage or disadvantage with respect to other stimuli in the display while maintaining discriminability $d^{\prime}$ at the same level. We observed a dramatic change in attentional cost. Thus it appears that the attentional cost of detection or search is determined not by discriminability $d^{\prime}$ but by competitive advantage or disadvantage with respect to other stimuli in the display. These findings are consistent with the existence of a "competition for saliency" that permits detection of salient stimuli independently of attention.
Further, we have applied the same concurrent-task paradigm to study the discrimination of various attributes of salient stimuli-for example, color, orientation, and shape - in the near absence of attention. Consistent with many previous studies, we find that letter shape is essentially indiscriminable under concurrent-task conditions. However, we also find that color and, to a lesser extent, orientation, is readily discriminated under concurrent-task conditions. This positive result overrides earlier studies with negative outcomes (Braun \& Sagi, 1990; Sagi \& Julesz, 1985) and suggests that, under some conditions, certain attributes of salient stimuli are discriminated independently of attention. That the discriminative ability in question extends to multiple attributes of multiple stimuli only strengthens this conclusion. We hypothesize that the extent to which stimulus attributes are discriminable without attention coincides with the extent to which such attributes are processed by early vision.

Our interpretation of these findings is that visual awareness is not limited to the currently attended region but extends to selected information from unattended regions of the field of view. We suspect that the selection of this information is accomplished by the mechanisms that underlie visual saliency. We envisage two levels of neural interactions - surround inhibition and global competition - which jointly determine the stimuli and attributes that elicit a strong neuronal response and, thus, the stimuli and attributes that reach visual awareness independently of attention.

\section{REFERENCES}

Allman, J. M., Miezin, F., \& McGuinness, E. (1985). Direction- and velocity-specific responses from beyond the classical receptive field in the middle temporal area (MT). Perception, 14, 105-126.

AllPORT, D. A. (1980). Attention and performance. In G. Claxton (Ed.), Cognitive psychology: New directions (pp. 43-67). London: Routledge \& Kegan Paul.

Bashinski, H. S., \& Bacharach, V. R. (1980). Enhancement of perceptual sensitivity as the result of selectively attending to spatial locations. Perception \& Psychophysics, 28, 241-248.

Ben-Av, M. B., SAGI, D., \& BraUn, J. (1992). Visual attention and perceptual grouping. Perception \& Psychophysics, 52, 277-294.

Bergen, J., \& Julesz, B. (1983). Parallel versus serial processing in rapid pattern discrimination. Nature, 303, 696-698.

BisIaCH, E., \& VALlaR, G. (1988). Hemineglect in humans. In F. Boller \& J. Grafman (Eds.), Handbook of neuropsychology (Vol. 1, pp. 195222). Amsterdam: Elsevier.

BonNel, A.-M., \& Miller, J. (1994). Attentional effects on concurrent psychophysical discriminations: Investigations of a sample size model. Perception \& Psychophysics, 55, 162-179.

Bonnel, A.-M., PossamaI, C. A., \& Schmitt, M. (1987). Early modulations of visual input: A study of attentional strategies. Quarterly Journal of Experimental Psychology, 39A, 757-776.

Bonnel, A.-M., Stein, J.-F., \& BertucC, P. (1994). Does attention modulate the perception of luminance changes? Quarterly Journal of Experimental Psychology, 44A, 601-626.

BrauN, J. (1994a). Shape-from-shading is independent of visual attention and may be a "texton." Spatial Vision, 7, 311-322.

BraLn, J. (1994b). Visual search among items of different salience: Removal of visual attention mimics a lesion in extrastriate area V4. Journal of Neuroscience, 14, 554-567.

BraUN, J. (1996). [Unpublished raw data.] 
Braun, J., \& Julesz, B. (1992, November). Early vision: Dichotomous or continuous? Paper presented at the annual meeting of the Psychonomic Society, St. Louis.

Braun J., \& Julesz, B. (1994, November). William James was right about "passive, involuntary, and effortless" attention. Paper presented at the annual meeting of the Psychonomic Society, St. Louis.

BraUN, J., \& KOCH, C. (1995). Stimulus competition as a mechanism of visual selection: Interaction between motion and orientation of contrasts. Investigative Ophthalmology \& Visual Science, 36(Suppl.), 3926.

BRAUN, J., \& SAGI, D. (1990). Vision outside the focus of attention. Perception \& Psychophysics, 48, 45-58.

BraUn, J., \& SAGI, D. (1991). Texture-based tasks are little affected by a second task which requires peripheral or central attentive fixation. Perception, 20, 483-500.

Bravo, M. J., \& NaKayama, K. (1992). The role of attention in different visual-search tasks. Perception \& Psychophysics, 51, 465-472.

Cheal, M., \& Lyon, D. R. (1994). Allocation of attention in texture segregation, visual search, and location-precuing paradigms. Quarterly Journal of Experimental Psychology, 47A, 49-70.

Chelazzi, L., Miller, E. K., DunCan, J., \& Desimone, R. (1993). A neural basis of visual search in inferior temporal cortex. Nature, 363, 345-347.

DAmasio, A. R. (1987). The brain binds entities and events by multiregional activation from convergence zones. Neural Computation, $\mathbf{1}$ 123-132.

Desimone, R. (1992). Neural circuits for visual attention in the primate brain. In G. Carpenter \& S. Grossberg (Eds.), Neural networks for vision \& image processing (pp. 343-364). Cambridge, MA: MIT Press.

DESIMONE, R., \& DUNCAN, J. (1995). Neural mechanisms of selective visual attention. Annual Review of Neuroscience, 18, 193-222.

Desimone, R., Schein, S. G., Moran, J., \& Ungerleider, L. G. (1985). Contour, color and shape analysis beyond the striate cortex. Vision Research, 25, 441-452.

Dick, M., UllmaN, S., \& SAGI, D. (1987). Parallel and serial processes in motion detection. Science, 237, 400-402.

Downing, C. (1988). Expectancy and visual-spatial attention:Effects on perceptual quality. Journal of Experimental Psychology: Human Perception \& Performance, 14, 188-202.

DunCAN, J. (1980a). The demonstration of capacity limitation. Cognitive Psychology, 12, 75-96.

DUNCAN, J. (1980b). The locus of interference in the perception of simultaneous stimuli. Psychological Review, 87, 272-300.

DUNCAN, J. (1984). Selective attention and the organization of visual information. Journal of Experimental Psychology: General, 113, $501-517$

DUNCAN, J. (1993). Similarity between concurrent visual discriminations: Dimensions and objects. Perception \& Psychophysics, 54, 425-430.

Duncan, J., WARD, R., \& ShaPIRO, K. (1994). Direct measurement of attentional dwell time in human vision. Nature, 369, 313-315.

ENNS, J. T., \& RENSINK, R. A. (1990). Influence of scene-based properties on visual search. Science, 247, 721-723.

ERIKSEN, C. W., \& ST. JAMES, J. D. (1986). Visual attention within and around the field of focal attention: A zoom lens model. Perception \& Psychophysics, 40, 225-240.

Felleman, D. J., \& VAN EsSEN, D. C. (1990). Distributed hierarchical processing in the primate cerebral cortex. Cerebral Cortex, 1, 1-47.

Gallant, J. L., Connor, C. E., \& Van Essen, D. C. (1994). Responses of visual cortical neurons in a monkey freely viewing natural scenes. Society for Neuroscience Abstracts, 20, 838.

GrEEN, D.. \& SwETs, J. (1966). Signal detectability and psychophysics. New York: Wiley.

GuRNSEY, R., \& Browse, R. A. (1987). Micropattern properties and presentation conditions influencing visual texture discrimination. Perception \& Psychophysics, 41, 239-252.

HaEnNy, P. E., Maunsell, J. H. R., \& Schiller, P. H. (1988). State dependent activity in monkey visual cortex: 2 . Retinal and extraretinal factors in V4. Experimental Brain Research, 69, 245-259.

Helmholtz, H. (1962). Treatise on physiological optics (J. P. C. Southall, Ed.). New York: Dover. (Original work published 1850)

JAMES, W. (1981). The principles of psychology. Cambridge, MA: Harvard University Press. (Original work published 1890)
JuLESZ, B. (1981). Textons, the elements of texture perception and their interactions. Nature, 290, 91-97.

JULESZ, B. (1984). Towards an axiomatic theory of preattentive vision. In G. M. Edelman, W. E. Gall, \& W. M. Cowan (Eds.), Dynamic as pects of neocortical function (pp. 585-612). Washington, DC: Neurosciences Research Foundation.

JULESZ, B. (1991). Early vision and focal attention. Review of Modern Physics, 63, 735-772.

Kahneman, D. (1973). Attention and effort. Englewood Cliffs, NJ: Prentice-Hall.

KARNI, A., \& SAGI, D. (1993). Later, but (almost) forever-The time course of learning a visual skill. Nature, 365, 250-252.

Karni, A., Tanne, D., Rubenstein, B. S., Askenasy, J. J. M., \& SAGI, D. (1994). Dependence on REM sleep of overnight improvement of a perceptual skill. Science, $\mathbf{2 6 5}, 679-682$

KINSBOURNE, M. (1993). Orientational bias model of unilateral neglect: Evidence from attentional gradients within hemispace. In I. H. Robertson \& J. C. Marshall (Eds.), Unilateral neglect: Clinical and experimental studies (pp. 63-86). Hillsdale, NJ: Erlbaum.

KNIERIM, J. J., \& VAN EsSEN, D. C. (1992). Neuronal responses to static texture patterns in area V1 of the alert macaque monkey. Journal of Neurophysiology, 67, 961-980.

KoCH, C., \& Ullman, S. (1985). Shifts in selective visual attention: Towards the underlying neural circuitry. Human Neurobiology, 4 , 219-227.

Kröse, B., \& JULESZ, B. (1989). The control and speed of shifts of attention. Vision Research, 29, 1607-1619.

KWAK, H., \& EGETH, H. [E.] (1992). Consequences of allocating attention to locations and other attributes. Perception \& Psychophysics, $51,455-464$.

LABERGE, D., \& BROWN, V. (1989). Theory of attentional operations in shape identification. Psychological Review, 96, 101-124.

Macmillan, N., \& Creelman, C. (1991). Detection theory: A user's guide. Cambridge: Cambridge University Press.

Malik, J., \& Perona, P. (1990). Preattentive texture discrimination with early vision mechanisms. Journal of the Optical Society of America A, 7, 923-932.

MAUNSELL, J. H. R. (1995). The brain's visual world-Representation of visual targets in cerebral cortex. Science, 270, 764-769.

Miller, E. K., GoCHIN, P. M., \& Gross, C. G. (1993). Suppression of visual responses of neurons in inferior temporal cortex of the awake macaque by addition of a second stimulus. Brain Research, 616, 25-29.

Moore, C. M., Egeth, H., Berglan, L. R., \& Luck, S. J. (1996). Are attentional dwell times inconsistent with serial visual search? Psychonomic Bulletin \& Review, 3, 360-365.

MoRAN, J., \& Desimone, R. (1985). Selective attention gates visual processing in the extrastriate cortex. Science, 229, 782-784.

MoRdKofF, J. T., YANTIS, S., \& EgETH, H. E. (1990). Detecting conjunctions of color and form in parallel. Perception \& Psychophysics, 48, 157-168.

MOTTER, B. C. (1993). Focal attention produces spatially selective processing in visual cortical areas V1,V2, and V4 in the presence of competing stimuli. Journal of Neurophysiology, 70, 909-919.

MotTER, B. C. (1994). Neural correlates of attentive selection for color or luminance in extrastriate area V4. Journal of Neuroscience, 14 2178-2189.

MÜLlER, H. J., \& Findlay, J. M. (1987). Sensitivity and criterion effects in the spatial cuing of visual attention. Perception \& Psychophysics, 42, 383-399.

NAKAYAMA, K. (1991). The iconic bottleneck and the tenuous link between early visual processing and perception. In C. Blakemore (Ed.) Vision, coding and efficiency (pp. 4l1-422). Cambridge: Cambridge University Press.

NaKaYAMA, K., \& MaCKEBEN, M. (1989). Sustained and transient components of focal visual attention. Vision Research, 29, 1631-1647.

NaKayama, K., \& Silverman, G. H. (1986). Serial and parallel processing of visual feature conjunctions. Nature, 320, 264-265.

NAVON, D., \& GopHER, D. (1979). On the economy of the human processing system. Psychological Review, 86, 214-255.

Norman, D., \& Bobrow, D. (1975). On data-limited and resourcelimited processes. Cognitive Psychology, 7, 44-64.

NothDURFT, H. C. (1990). Texton segregation by associated differences 
in global and local luminance distribution. Proceedings of the Royal Society London: Series B, 239, 295-320.

NoTHDURFT, H. C. (1991). Texture segmentation and pop-out from orientation contrast. Vision Research, 31, 1073-1078.

Pashler, H. (1987). Detecting conjunctions of color and form: Reassessing the serial search hypothesis. Perception \& Psychophysics, 41, 191-201.

Pashler, H. (1994). Dual-task interference in simple tasks-Data and theory. Psychology Bulletin, 116, 220-244.

Press, W. A., KNierim, J. J., \& VAN Essen, D. C. (1994). Neuronal correlates of attention to texture patterns in macaque striate cortex. Society for Neuroscience Abstracts, 20, 838.

Press, W. H., Teukolsky, S., Vetterling, W., \& Flannery, B. (1992). Numerical recipes in $C$ : The art of scientific computing ( $2 \mathrm{nd}$ ed.). Cambridge: Cambridge University Press.

Reynolds, J., Chelazzi, L., Luck, S., \& Desimone, R. (1994). Sensory interactions and effects of selective spatial attention in macaque area V2. Society for Neuroscience Abstracts, 20, 1054.

Reynolds, J., Nicholas, J., Chelazzi, L., \& Desimone, R. (1995). Spatial attention protects macaque $\mathrm{V} 2$ and $\mathrm{V} 4$ cells from the influence of non-attended stimuli. Society for Neuroscience Abstracts, 21, 1759.

Robinson, D. L., \& Petersen, S. E. (1992). The pulvinar and visual salience. Trends in Neurosciences, 15, 127-132.

RUBENSTEIN, B., \& SAGI, D. (1990). Spatial variability as a limiting factor in texture-discrimination tasks: Implications for performance asymmetries. Journal of the Optical Society of America A, 7, 1632-1642.

Rummelhart, D., \& McClelland, J. L. (1986). Parallel distributed processing: Explorations in the microstructure of cognition. Cambridge, MA: MIT Press.

SAGI, D. (1990). Detection of an orientation singularity in Gabor textures: Effect of signal density and spatial frequency. Vision Research, 30, 1377-1390.

SAGI, D., \& JULESZ, B. (1985). Where and what in vision. Science, 228, 1217-1219

SAGI, D., \& Julesz, B. (1987). Short-range limitation on detection of feature differences. Spatial Vision, 1, 39-49.

SATO, T. (1995). Interactions between two different visual stimuli in the receptive fields of inferior temporal neurons in macaques during matching behaviors. Experimental Brain Research, 105, 209-219.

SCHILlER, P. H., \& LEE, K. (1991). The role of primate extrastriate area V4 in vision. Science, 251, 1251-1253.

SHAW, M. L. (1984). Division of attention among spatial locations: A fundamental difference between detection of letters and detection of luminance increments. In H. Bouma \& D. G. Bouwhuis (Eds.), Attention and performance $X$ (pp. 109-121). London: Psychology Press.

SPERLING, G., \& Dosher, B. (1986). Strategy and optimization in human information processing. In K. R. Boff, L. Kaufman, \& J. P. Thomas (Eds.), Handbook of perception and human performance (pp. 1-65). New York: Wiley.

SPERLING, G., \& MELCHNER, M. J. (1978). The attention operating characteristic: Some examples from visual search. Science, 202, 315-318.

SPITZER, H., DESIMONE, R., \& MORAN, J. (1988). Increased attention en- hances both behavioral and neural performance. Science, 240, 338340.

SUn, J. Y., \& Perona, P. (1996). Preattentive perception of elementary 3-dimensional shapes. Vision Research, 36, 2515-2529.

Treisman, A. (1988). Features and objects: The Fourteenth Bartlett Memorial Lecture. Quarterly Journal of Experimental Psychology, 40A, 201-237.

TreISMAN, A. (1993). The perception of features and objects. In A. Baddeley \& L. Weiskrantz (Eds.), Attention: Selection, awareness, and control (pp. 1-35). Oxford: Oxford University Press, Clarendon Press.

Treisman, A., \& Gelade, G. (1980). A feature integration theory of attention. Cognitive Psychology, 12, 97-136.

Treisman, A., \& GoRMICAN, S. (1988). Feature analysis in early vision: Evidence from search asymmetries. Psychological Review, 12, 97-136.

Treisman, A., \& Souther, J. (1985). Search asymmetry: A diagnostic for preattentive processing of separable features. Journal of Experimental Psychology: General, 114, 285-310.

VAN EsSEN, D. C., \& GaLlant, J. L. (1994). Neural mechanisms of form and motion processing in the primate visual system. Neuron, 13, 1-10.

WatT, R. (1991). Seeing texture. Cognitive Neuroscience, 1, 137-139.

WeIBULL, W. A. (1951). A statistical distribution function of wide applicability. Journal of Applied Mechanics, 18, 292-297.

WEN, J., KOCH, C., \& BRAUN, J. (1995). Visual tracking of multiple moving objects requires modality-specific attention. Investigative Ophthalmology \& Visual Science, 36(Suppl.), 4133.

WEN, J., KoCH, C., \& BraUn, J. (1996). Spatial vision outside the focus of attention. Investigative Ophthalmology \& Visual Science, 37(Suppl.), 532.

Williams, D. W., \& JULESZ, B. (1991). Filters versus textons in human and machine texture discrimination. In $\mathrm{H}$. Wechsler (Ed.), Neural networks for human \& machine perception (pp. 201-233). Orlando, FL: Academic Press.

WolfE, J. M. (1994). Guided search 2.0: A revised model of visual search. Psychonomic Bulletin \& Review, 1, 202-238.

WolfE, J. M. (in press). Visual search. In H. Pashler (Ed.), Attention. London: University College London Press.

\section{NOTES}

1. We ignore here that the task in question involved not only the detection but also the crude localization of a pop-out.

2 . The intrinsic detectability of a stimulus can be defined as the detectability that is measured when the stimulus is removed from its context and presented in an otherwise empty display. Larger, brighter, more chromatic, or more coarsely patterned stimuli tend to be intrinsically more detectable than smaller, dimmer, less chromatic, or more finely patterned stimuli, respectively.

3. Target size was was $1.4^{\circ}$ in Experiment $6,79^{\circ}$ in Experiment $4,0.14^{\circ}-$ $0.50^{\circ}$ in Braun and Sagi (1990), and $0.48^{\circ}$ in Sagi and Julesz (1985).

(Manuscript received November 21, 1995; revision accepted for publication January 7,1997 .) 